\title{
Casein kinase 1a: biological mechanisms and theranostic potential
}

Shaojie Jiang ${ }^{1+}$, Miaofeng Zhang ${ }^{2+}$, Jihong Sun ${ }^{1}$ and Xiaoming Yang ${ }^{1,3^{*}}$ (D)

\begin{abstract}
Casein kinase $1 \mathrm{a}(\mathrm{CK} 1 \mathrm{a})$ is a multifunctional protein belonging to the CK1 protein family that is conserved in eukaryotes from yeast to humans. It regulates signaling pathways related to membrane trafficking, cell cycle progression, chromosome segregation, apoptosis, autophagy, cell metabolism, and differentiation in development, circadian rhythm, and the immune response as well as neurodegeneration and cancer. Given its involvement in diverse cellular, physiological, and pathological processes, CK1a is a promising therapeutic target. In this review, we summarize what is known of the biological functions of CK1a, and provide an overview of existing challenges and potential opportunities for advancing theranostics.
\end{abstract}

Keywords: Casein kinase 1a, Wnt/ß-catenin signaling, NF-kB signaling, Hedgehog signaling, Autophagy, Neurodegenerative disease, Cell cycle, Host defense response

\section{Background}

Casein kinase $1 \alpha(\mathrm{CK} 1 \alpha)$ (encoded by CSNK1A1 in humans) is a member of the CK1 family of proteins that has broad serine/threonine protein kinase activity [1-4] (Fig. 1a) and is one of the main components of the Wnt/ $\beta$-catenin signaling pathway. CK1 $\alpha$ phosphorylates $\beta$-catenin at Ser45 as part of the $\beta$-catenin destruction complex for subsequent $\beta$-transducin repeat-containing E3 ubiquitin protein ligase $(\beta-\operatorname{Tr} C \mathrm{P})$-mediated ubiquitination and proteasomal degradation $[5,6]$. Recent studies have shown that CK1 $\alpha$ targets p53 for degradation-which is mediated by murine double minute clone 2 (MDM2) and MDM4 (also known as MDMX) [7-10]-while stabilizing and thereby positively regulating E2F-1, a transcription factor involved in cell cycle progression [7]. Additionally, CK1 $\alpha$ was shown to exert dual gating functions by first promoting and then terminating $\mathrm{T}$ cell receptor (TCR)-induced nuclear factor $\kappa B(\mathrm{NF}-\mathrm{kB})$ activation [11]. Lenalidomide (a thalidomide analog) is a highly effective treatment for myelodysplastic syndrome with

\footnotetext{
* Correspondence: xmyang@zju.edu.cn; xmyang@uw.edu

'Shaojie Jiang and Miaofeng Zhang contributed equally to this work.

'Department of Radiology, Sir Run Run Shaw Hospital, School of Medicine,

Zhejiang University, Zhejiang 310016, Hangzhou, China

${ }^{3}$ Image-Guided Bio-Molecular Intervention Research, Department of

Radiology, University of Washington School of Medicine, Seattle, WA 98109,

USA

Full list of author information is available at the end of the article
}

deletion of chromosome $5 \mathrm{q}$ [MDS $\operatorname{del}(5 \mathrm{q})]$ that exerts its effects by inducing CK1 $\alpha$ ubiquitination and degradation $[12,13]$. These findings suggest that CSNK1A1 is a conditionally essential malignancy gene and a potential target for anti-cancer drugs.

\section{Overview of CK1a}

CSNK1A1 is located on chromosome $5 \mathrm{q} 32$ and is expressed as four alternatively spliced transcript variants, yielding four protein isoforms of varying length that mainly differ by the presence or absence of a 28 -amino acid " $\mathrm{L}$ " insert in the kinase domain and a 12-amino acid " $\mathrm{S}$ " insert near the $\mathrm{C}$ terminus. The former is unique to vertebrates [14] and contains the sequence of PVGKRKR, which has the characteristics of a nuclear localization signal (NLS) and may target CK1 $\alpha$ to the nucleus [15] (Fig. 1b). Isoform 2, which comprises 337 amino acids, is the predominant isoform $[11,13]$ with a kinase domain located between Ile12 and Ala282 [11]. The $2.45-\AA$ crystal structure revealed that the first 93 amino acids form a $\beta$-hairpin loop and (especially residues 35-41) binds cullin 4/really interesting new gene-box 1/DNA damage-binding protein 1/cereblon (CRBN) (also known as CRL4 ${ }^{\text {CRBN }}$ ) E3 ubiquitin ligase for CK1 $\alpha$ ubiquitination and degradation $[12,13]$. The C-lobe of CK1 $\alpha$ is mainly composed of $\alpha \mathrm{C}$ helices and contributes to the kinase function (Fig. 1c). CK1 $\alpha$ 

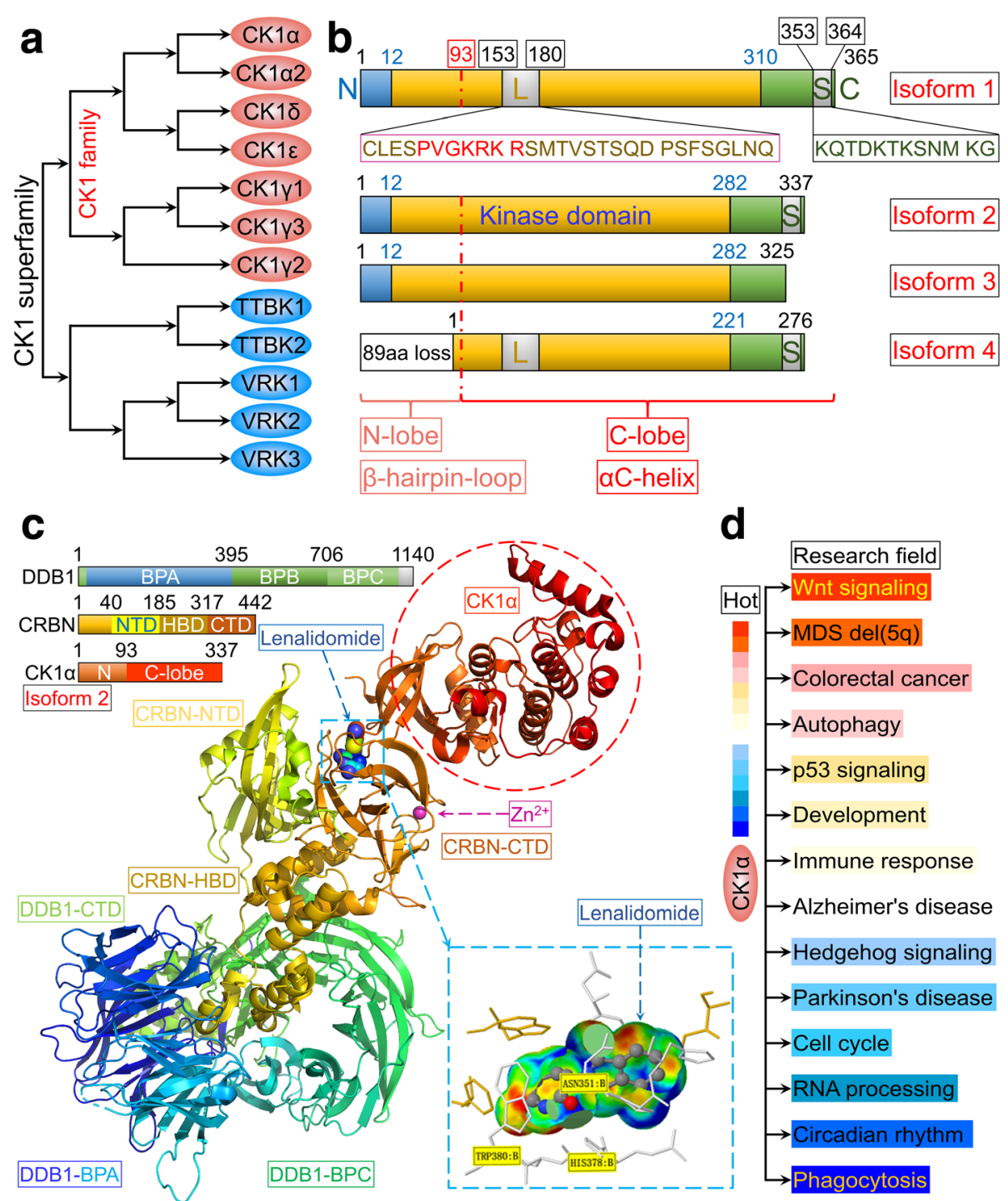

Fig. 1 Schematic representation of CK1a. a CK1 family and CK1 superfamily. b Four isoforms of CK1a and their functional domains. c Cartoon representation of DNA damage-binding protein (DDB)1 $\triangle B P B-C R B N-l e n a l i d o m i d e-C K 1 a$. Top left, DDB1, CRBN, and CK1a domain color coding and boundaries. Bottom right, enlarged view of the CRBN-lenalidomide-CK1 a interface (data were obtained from protein data bank: www.rcsb.org, PDB-ID: 5FQD; and were first published in reference [13]). $\mathbf{d}$ Investigations on CK1a in diverse research fields

phosphorylates the serine/threonine residue in the canonical motif of $\mathrm{pS} / \mathrm{T}-\mathrm{X}_{(n=2-4)}$ - $\mathrm{pS} / \mathrm{T}$ or noncanonical motif of $\mathrm{pS} / \mathrm{T}-\mathrm{X}-\mathrm{pS} / \mathrm{T}$ (where $\mathrm{pS} / \mathrm{T}$ is phospho-serine/ threonine and $\mathrm{X}$ is any amino acid) [16, 17]. The basic residues $\left(\mathrm{K}^{229} \mathrm{KQK}^{232}\right)$ of $\mathrm{CK} 1 \alpha$ are implicated in canonical substrate recognition [17], but the noncanonical substrate with $\mathrm{pS} / \mathrm{T}-\mathrm{X}$-pS/T motif such as $\beta$-catenin is not significantly affected by mutations in the $\mathrm{K}^{229} \mathrm{KQK}^{232}$ stretch $[17,18]$.

CK1 $\alpha$ is widely expressed in various organelles including the cell membrane and nucleus [15]. It also localizes to the centrosome, microtubules, the Golgi apparatus, and endoplasmic reticulum in non-neuronal interphase cells [19, 20]; in synaptic vesicles in neurons [20]; spindle microtubules at mitosis [21]; and to nuclear structures (e.g., nuclear speckles) [22]. CK1 $\alpha$ is ubiquitously expressed and is constitutively active [23, 24], implying that it has many biological functions besides its role in $\beta$-catenin degradation that span diverse research areas (Fig. 1d).

\section{Physiological and pathological expression of CK1a in humans}

CK1 $\alpha$ mRNA is expressed in all tissues in humans under physiological conditions; the levels are high in esophagus and skin, but low in pancreas and liver (Fig. 2a). The protein is highly expressed in adrenal gland, bronchus, testis, placenta, and endometrium but is not detected in smooth 


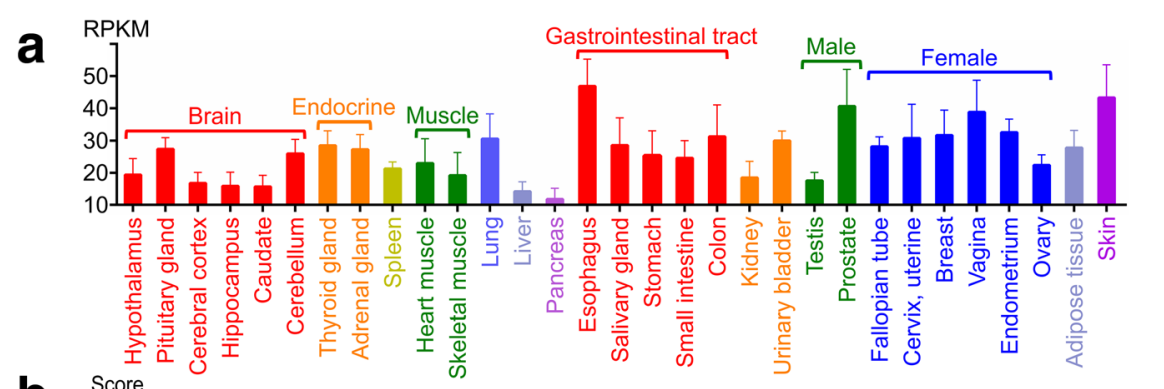

b
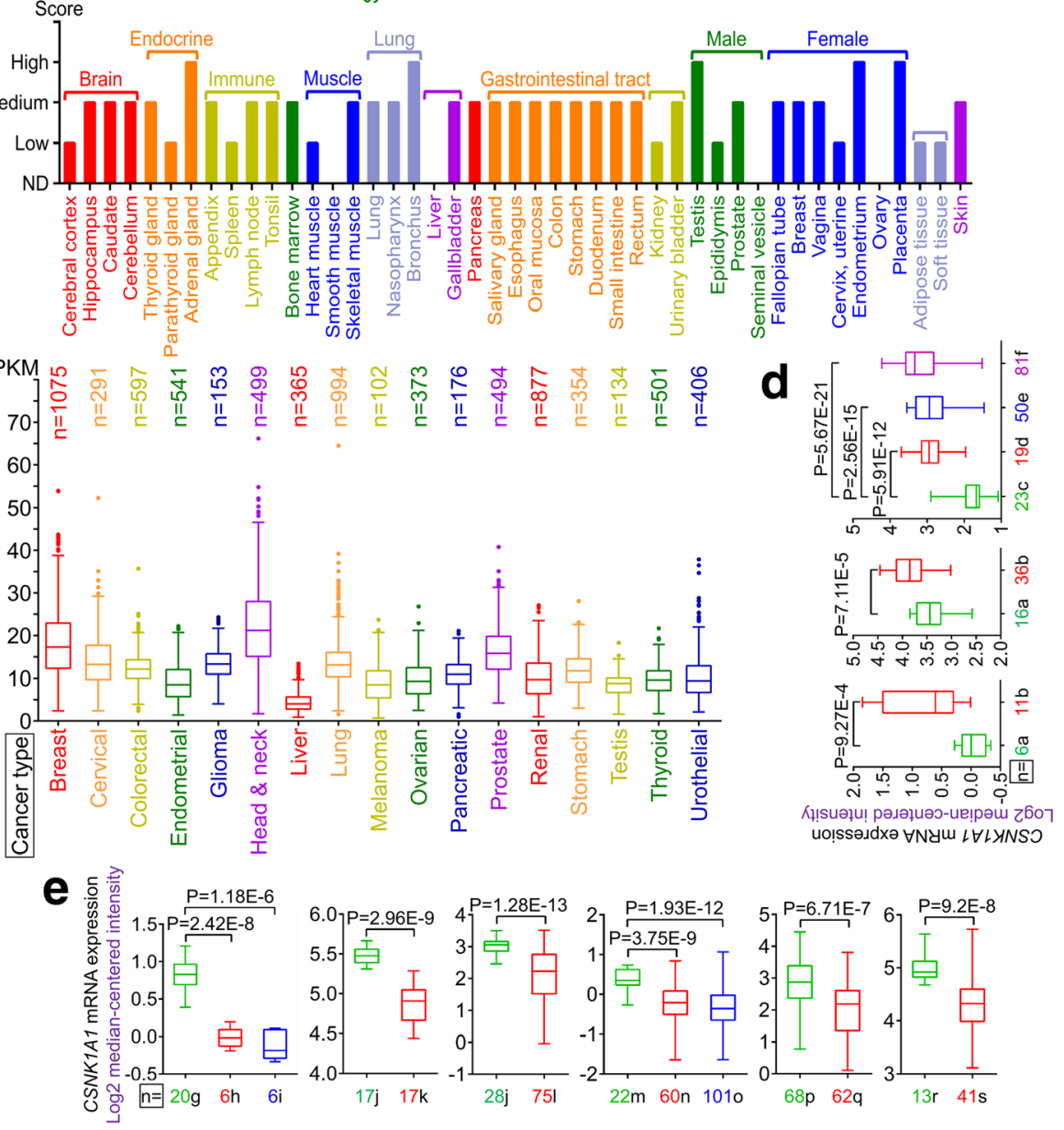

Fig. 2 CK1a expression in normal human tissues and the most common human cancer tissues. a RNA sequencing data for CK1a expressed in normal human tissues are reported as median reads per kilobase per million mapped reads (RPKM). The data were generated by the Genotype-Tissue Expression project (www.gtexportal.org) and were first published in references $[238,239]$ and deposited in the HPA (www.proteinatlas.org). b Protein expression data from HPA (www.proteinatlas.org), first published in reference [240]. c RNA sequencing data of CK1 a levels in 17 cancer types are reported as median number of fragments per kilobase of exon per million reads (FPKM), generated by The Cancer Genome Atlas (TCGA) (https://cancergenome.nih.gov/); data were first published in reference [241], and were deposited in the HPA (www.proteinatlas.org). d, e Microarray data of CK1a expression in normal and cancer tissues in humans were obtained from Oncomine (www.oncomine.org) (reference [242]). Differences in expression levels were evaluated with the Student's t test using Oncomine software. $\mathbf{d}$ Upregulation of CK1 a mRNA levels in human cancer tissues relative to matched normal tissues. a, Pancreas, b, pancreatic carcinoma (left, reference [243] and right, reference [244]); c, brain; d, anaplastic astrocytoma; e, oligodendroglioma; f, glioblastoma (reference [245]). e Downregulation of CK1 a mRNA levels in human cancer tissues relative to matched normal tissues. g, CD4-positive $(n=5)+$ CD8-positive $(n=5)+$ normal T lymphocytes $(n=10)$; $h$, angioimmunoblastic T-cell lymphoma; i, anaplastic large cell lymphoma (reference [246]); j, esophagus; $k$, esophageal squamous cell carcinoma; I, esophageal adenocarcinoma (left, reference [247]; right, reference [248]); $\mathrm{m}$, colon $(n=19)+$ rectum $(n=3) ; \mathrm{n}$, rectal adenocarcinoma; o, colon adenocarcinoma (data obtained from TCGA and deposited in Oncomine); p, bladder mucosa; q, infiltrating bladder urothelial carcinoma (reference [249]); r, buccal mucosa; s, head and neck squamous cell carcinoma (reference [250]) 
muscle, liver, seminal vesicle, or ovary (Fig. 2b). CK1 $\alpha$ mRNA is expressed in most cancer tissues (Fig. 2c), and highly expressed in pancreatic cancer but is detected at low levels in colorectal cancer as compared to matched normal tissues with GeneChip arrays (Fig. 2d, e). Interestingly, low CK1 $\alpha$ expression was associated with poorer overall survival (OS) in colorectal cancer patients (Fig. 3a-c), especially in colon adenocarcinoma (Fig. $3 \mathrm{~d}-\mathrm{i}$ ). On the other hand, high CK1 $\alpha$ levels in pancreatic cancer were linked to poorer OS (Fig. 3j-l), providing evidence that $\mathrm{CK} 1 \alpha$ is a conditionally essential malignancy protein. CK1 $\alpha$ mRNA was also found to be expressed in various cancer cell lines (Fig. 4a) and was localized to the cytosol (Fig. 4b), suggesting that it mainly functions in the cytoplasm.

\section{CK1a in Wnt/ $\beta$-catenin and hedgehog signaling}

$\mathrm{Wnt} / \beta$-catenin (also known as canonical Wnt) signaling regulates various physiological processes including embryonic development, adult stem cell maintenance, and genomic stability [25]. Mutations in Wnt pathway components such as adenomatous polyposis coli (APC) result in pathological disturbances, especially in colorectal cancer [26]. $\beta$-catenin is a key component of this pathway that binds to the cytoplasmic tail of E-cadherin at the cell membrane to promote cell-cell adhesion [27], and also localizes to the cytoplasm where it forms the destruction complex along with $\mathrm{CK} 1 \alpha$, glycogen synthase kinase $3 \beta$ (GSK-3 $\beta$ ), APC, Axin, and Wilms tumor gene on X chromosome (WTX, also known as APC membrane recruitment protein 1) to promote the ubiquitination and proteasomal degradation of $\beta$-catenin in the absence of extracellular Wnt ligands [28]. $\beta$-Catenin is translocated to the nucleus upon activation of Wnt signaling via Rac1 [29], where it forms a complex with $\mathrm{T}$ cell factor and co-activators such as cyclic (c)AMP response element-binding protein
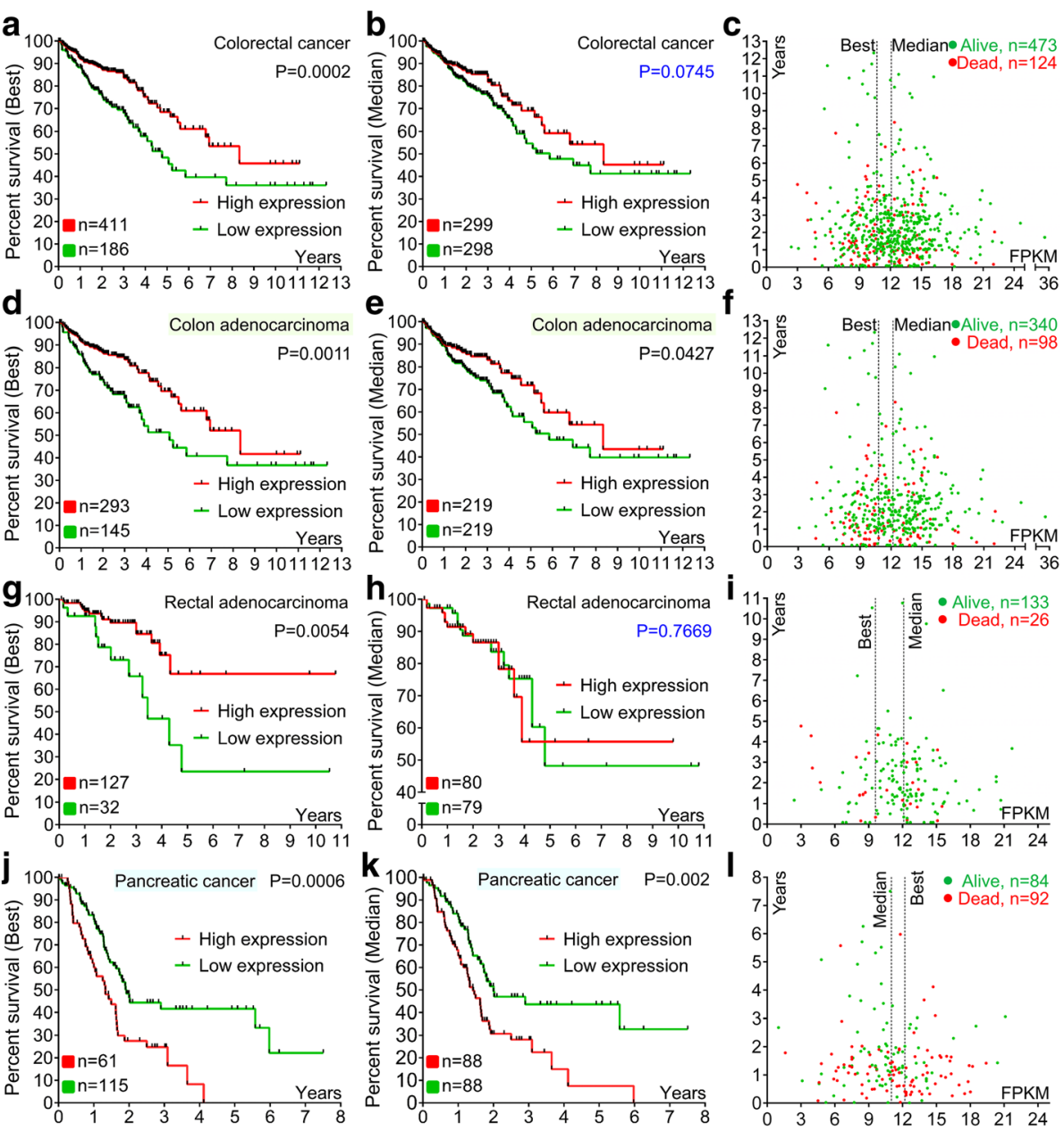

Fig. 3 Prognostic value of CK1a mRNA level in human colorectal and pancreatic cancers. Data were obtained from The Cancer Genome Atlas and deposited in the HPA (www.proteinatlas.org). $P$ values were estimated with the Kaplan-Meier method. $\mathbf{a}, \mathbf{b}, \mathbf{d}, \mathbf{e}, \mathbf{g}, \mathbf{h}, \mathbf{j}, \mathbf{k}$ Kaplan-Meier survival analysis of colorectal cancer, colon adenocarcinoma, rectal adenocarcinoma, and pancreatic cancer by best (left) and median (right) separation according to CK1a mRNA expression level. $\mathbf{c}, \mathbf{f}, \mathbf{i}, \mathbf{I}$ Interactive survival plot (individual patient data) 

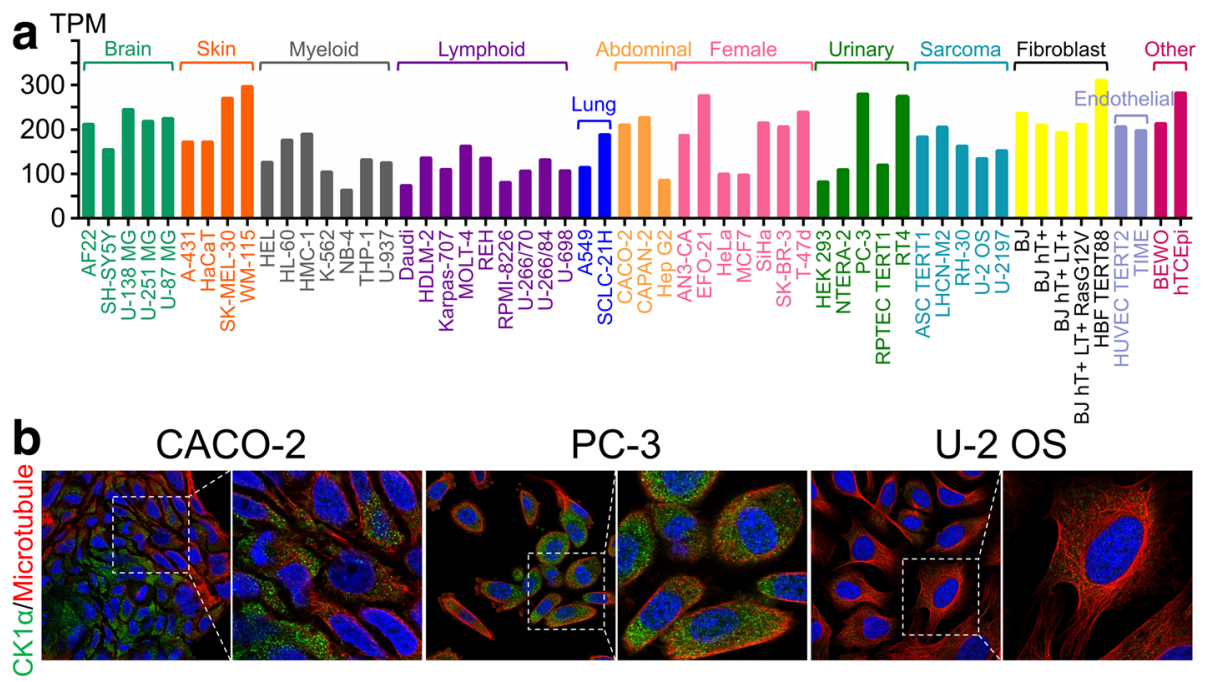

Fig. 4 CK1 a mRNA and protein expression in common cell lines. a RNA sequencing data for CK1a from the HPA (www.proteinatlas.org) are reported as number of transcripts per kilobase million. b Subcellular localization of CK1a in Caco-2, PC-3, and U-2 OS cell lines. Data were obtained from the HPA (www.proteinatlas.org) and were first published in reference [251]

(CREB)-binding protein and BRM/SWI2-related gene 1 (Brg-1) to activate Wnt target genes [30].

$\beta$-Catenin is phosphorylated by CK1 $\alpha$ at Ser45, which leads to GSK-3 $\beta$-dependent phosphorylation at Ser33/37 and Thr41 and subsequent degradation [5]. APC is also phosphorylated at Ser1504/1505/1507 and S1510 (in the R3 region) by CK1 $\alpha$ and other CK1 proteins [31], which is essential for $\beta$-catenin binding. Thus, CK $1 \alpha$ acts as a negative regulator of Wnt signaling [32].

The cytoplasmic domain of E-cadherin is phosphorylated by CK1 $\alpha$ at Ser846, which attenuates its interaction with while promoting the release of $\beta$-catenin from the cell membrane [33]. Low-density lipoprotein receptor-related protein 6 (LRP6) is a single-pass transmembrane receptor that cooperates with Frizzled proteins for Wnt ligand binding and can be phosphorylated by CK1 $\alpha$ and CK1 $\delta$ at Thr1493, which activates and promotes recruitment of Axin to the membrane in response to the Wnt signal, leading to Wnt pathway activation [34]. The plant homeodomain zinc finger protein Jade-1 functions as an E3 ubiquitin ligase that ubiquitinates both phosphorylated and non-phosphorylated forms of $\beta$-catenin [35] and is a substrate of CK1 $\alpha$; it is phosphorylated at Ser18 and Ser20, which reduces its ability to inhibit Wnt/ $\beta$-catenin signaling $[36,37]$. Thus, CK1 $\alpha$ can act as a positive regulator of $\mathrm{Wnt} / \beta$-catenin signaling (Fig. $5 \mathrm{a}$ and Table 1).

The development of the Cre-LoxP system has enabled detailed investigations of the opposing functions of CK1 $\alpha$ in Wnt signaling. For example, gut-specific knockout of CK1 $\alpha$ using the Villin 1 promoter resulted in Wnt hyperactivation due to decreased phosphorylation of $\beta$-catenin at Ser45, Ser33/37, and Thr41 and an increment in total $\beta$-catenin levels. Accordingly, target genes of Wnt signaling such as cyclin D1, c-myc, and CD44 were induced at both the mRNA and protein levels in CK1 $\alpha$ knockout mice [10]. Reporter-based screens of haploid human cells revealed that CK1 $\alpha$ and APC were the rate-limiting negative regulators of Wnt signaling [38].

Hedgehog signaling is aberrantly activated in basal cell carcinomas, the most common cancer in humans [39] and in medulloblastoma, the most common pediatric brain malignancy [40]. Gli transcription factors are key mediators of Hedgehog signaling and are phosphorylated by CK $1 \alpha$, GSK- $3 \beta$, and protein kinase A (PKA), which promote the proteolysis of the active form of Gli1/2 and induction of a repressive form of Gli3 receptor [41]. In Drosophila, CK1 $\alpha$ suppresses Hedgehog signaling in the absence of a ligand [42, 43] and is also required for Smoothened (Smo) phosphorylation upon pathway activation [44-48]. However, Smo in mammals lacks CK1 $\alpha$ phosphorylation sites [47].

Hedgehog signaling shares many components with the Wnt $/ \beta$-catenin pathway, including CK1 $\alpha$, GSK-3 $\beta$, and $\beta$-TrCP $[49,50]$. Pyrvinium, a CK1 $\alpha$ agonist that is known to block Wnt signaling [51], suppresses Hedgehog signaling by attenuating Gli activity [52]. Thus, CK1 $\alpha$ functions as a negative regulator of Hedgehog signaling in mammals (Fig. 5b).

\section{CK1a in the regulation of autophagy}

Autophagy plays an important role in the maintenance of organismal homeostasis through regulation of cellular protein and organelle turnover, with their subsequent 


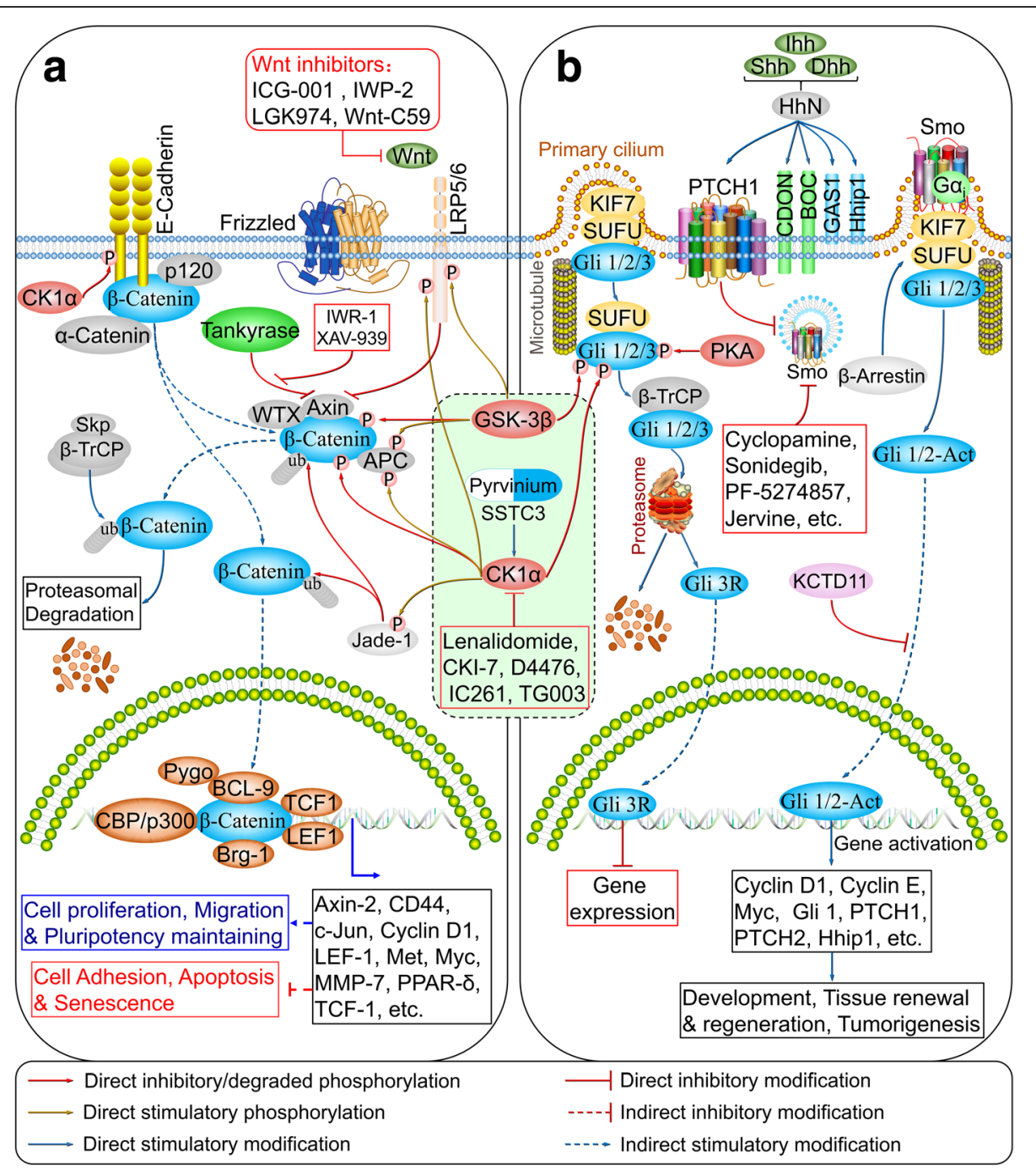

Fig. 5 CK1a mediates crosstalk between Wnt/ $\beta$-catenin and Hedgehog signaling networks. a, b CK1a in Wnt/ $\beta$-catenin (a) and Hedgehog (b) signaling pathways. (also reviewed in references $[41,252]$ )

degradation by lysosomes providing macromolecular precursors and energy to cells [53]. Aberrant autophagy leads to various diseases such as cancer and neurodegeneration [54]. Autophagy is an evolutionarily conserved catabolic process that has five distinct stages: initiation, vesicle nucleation, vesicle elongation, vesicle fusion, and cargo degradation [54]. It is induced by nutrient deficiency, oxidative stress, and infection, among other factors. Vesicle nucleation is induced by an activated Unc-51-like autophagy activating kinase 1 (ULK1) complex, which consists of ULK1/2 (ortholog of yeast autophagy-related 1 [Atg1]), focal adhesion kinase family interacting protein of $200 \mathrm{kDa}$ (ortholog of yeast Atg17) [55], Atg13, and Atg101 [56, 57], which is released from mammalian target of rapamycin (mTOR) inhibition [58]. Beclin-1 is then phosphorylated by ULK1 and serves as a scaffold for the class III phosphatidylinositol-3 kinase
(PI3K) complex, promoting the localization of autophagy proteins to the phagophore [59]. During this process, autophagy and Beclin-1 regulator 1 binds to Beclin-1 (ortholog of yeast Atg6) to stabilize the PI3K complex, while Barkor (ortholog of yeast Atg14), ultraviolet radiation resistance-associated gene protein, and p150 (ortholog of yeast vacuolar protein sorting-associated protein 15 [Vps15]) bind to Beclin-1 to promote its interaction with Vps34 and phagophore formation [59-64]. Vesicle elongation is mediated by Atg12Atg5 [65] and microtubule-associated protein 1A/ 1B-light chain 3-II (LC3-II) [66] along with LC3-like molecules such as gamma-aminobutyric acid type A receptor-associated proteins (GABARAPs) [67], leading to the formation of an autophagosome. Atg12Atg5 conjugation is mediated by the E1-like enzyme Atg7 and E2-like enzyme Atg10 [65], while LC3B 
Table 1 Substrates of human CK1a in major cell signaling pathways

\begin{tabular}{|c|c|c|c|c|}
\hline Gene & Protein & Phosphorylation site & Pathway & Reference \\
\hline APC & APC & S1504, S1505, S1507, S1510 & Wnt/ $\beta$-Catenin & {$[31]$} \\
\hline CTNNB1 & $\beta$-Catenin & S45 & & {$[5,6]$} \\
\hline $\mathrm{CDH} 1$ & E-cadherin & S846 & & [33] \\
\hline LRP6 & LRP6 & Т1493 & & {$[34]$} \\
\hline JADE1 & JADE1 & $\mathrm{S} 18, \mathrm{~S} 20$ & & {$[36,37]$} \\
\hline $\mathrm{FOXO3A}$ & $\mathrm{FOXO3A}$ & S318, S321 & Autophagy & [72] \\
\hline DEPTOR & DEPTOR & S286, S287, S291 & & {$[74,75]$} \\
\hline SQSTM1 & SQSTM1/p62 & S349 & & [79] \\
\hline BCL10 & BCL10 & N/A & $N F-K B$ & {$[11,260]$} \\
\hline CARD11 & CARMA1 & 5608 & & {$[11,260]$} \\
\hline MALT1 & MALT1 & N/A & & {$[11,260]$} \\
\hline FADD & FADD & S194 & & {$[80,86]$} \\
\hline RELA & NF-kB/p65 & S316 & & [261] \\
\hline RIPK1 & RIP1 & a.a. $293-558$ & & [83] \\
\hline TNFRSF1A & TNFR1/p55 & N/A & & {$[83]$} \\
\hline TNFRSF1B & TNFR2/p75 & N/A & & {$[84]$} \\
\hline YBX1 & YB-1 & S176 & & {$[89]$} \\
\hline CDC25A & CDC25A & S79, S82 & Cell cycle & {$[92,93]$} \\
\hline MDM2 & MDM2 & N/A & & {$[7,95]$} \\
\hline MDM4 & MDMX & S289 & & {$[8,9,96]$} \\
\hline MYC & c-Myc & S252 & & [94] \\
\hline TP53 & P53 & S20 & & {$[97]$} \\
\hline YWHAQ & $14-3-3 \tau$ & S233 & & [101] \\
\hline YWHAZ & $14-3-3 \zeta$ & T233 & & [101] \\
\hline BACE1 & $\beta$-Secretase 1 & $\$ 498$ & Alzheimer's disease & [113] \\
\hline KCNIP3 & Calsenilin & S63 & & {$[115]$} \\
\hline CREB1 & CREB & S108, S111, S114 & Parkinson's disease & [128] \\
\hline LRRK2 & PARK8 & S910, S935, S955, S973 & & [131] \\
\hline PARK2 & Parkin & S101, S378 & & [132] \\
\hline SNCA & a-Synuclein & S87, S129 & & {$[126]$} \\
\hline CDK5 & CDK5 & S159 & & [134] \\
\hline
\end{tabular}

(ortholog of yeast Atg8) is cleaved at the $\mathrm{C}$ terminus by Atg4B protease to generate cytosolic LC3-I, which is conjugated to phosphatidylethanolamine by Atg7-Atg3, yielding lipidated LC3-II [66]. Finally, syntaxin 17 facilitates autophagosome fusion with the lysosome for autophagolysosome formation [68], with the cargo then degraded under low-pH conditions (also reviewed in references [53, 54]).

Among the above-mentioned autophagy-related genes, LC3B, GABARAPs (including GABARAP, GABARAPL1, and GABARAPL2), Atg4B, Atg12, and ULK2 were shown to be directly regulated by the transcription factor Forkhead box protein O3A (FOXO3A) [69-71], which is a CK1 $\alpha$ substrate that is phosphorylated at Ser318 and Ser321. Treatment with the CK1 inhibitor D4476 or short interfering RNA siRNA-mediated knockdown of $\mathrm{CK} 1 \alpha$ results in nuclear accumulation of FOXO3A and increased expression of autophagy-related genes. CK $1 \alpha$ protein abundance is regulated by $\mathrm{PI} 3 \mathrm{~K} / \mathrm{mTOR}$ signaling induced by activated or oncogenic/mutant RAS [72]. DEP domain-containing mTOR-interacting protein (DEPTOR), an mTOR inhibitor [73], is also phosphorylated by CK1 $\alpha$ at Ser286/287/291 after priming phosphorylation by mTOR for subsequent degradation mediated by $\beta$-TrCP [74-76]. CK1 $\alpha$ inhibition by D4476 or siRNA treatment results in upregulation of DEPTOR followed by suppression of mTOR signaling and induction of autophagy $[75,76]$. CK $1 \alpha$ is a key 
modulator of autophagic flux, and CSNK1A1 knockout mediated by transcription activator-like effector nucleases accelerated the turnover of long-lived proteins [77]. A similar observation was made in a previous study demonstrating that CSNK1A1 knockdown strongly induced autophagic flux [78]. Thus, CK1 $\alpha$ negatively regulates autophagy.

Sequestosome 1 (SQSTM1) (also known as p62)an autophagy adaptor/receptor and LC3-binding protein that targets specific substrates to autophagosomes [53]-is also phosphorylated by CK1 isoforms at Ser349 upon accumulation of dysfunctional proteins. Phosphorylated SQSTM1 accelerates the formation of inclusion bodies and autophagic protein clearance [79]. However, the induction of autophagy by CK1-mediated phosphorylation of SQSTM1 requires confirmation by co-immunoprecipitation and loss-of-function studies. The combination of $C K 1 \alpha$ suppression and treatment with lysosome inhibitors such as chloroquine leads to accumulation of ineffective autophagosomes that deprive cancer cells of nutrients required for growth, resulting in their death [72]. CK1 $\alpha$ therefore is a promising target for drugs that can be used in combination with lysosome inhibitors, especially in RAS-driven and mTOR-activated cancers [72, 80] (Fig. 6 and Table 1). Notably, there is a discrepancy in the action modes of CK1 $\alpha$ in non-small-cell lung cancer (NSCLC) versus RAS-driven colon cancer. CK1 $\alpha$ overexpression potently induces autophagic flux in NSCLC via the PTEN/AKT/ FOXO3A/Atg7 axis. It stabilizes phosphatase and tensin homolog deleted on chromosome ten (PTEN) by abrogating PTEN phosphorylation and antagonizing neural precursor cell expressed, developmentally down-regulated 4-1 (NEDD4-1) induced PTEN polyubiquitination, which suppresses NSCLC cell growth [81]. CK1 $\alpha$ exhibits dual functions in autophagy regulation based on these evidences.

\section{CK1a in NF-KB signaling}

$\mathrm{NF}-\mathrm{kB}$ signaling is a complex signaling pathway involved in innate and adaptive immunity, inflammation, lymphocyte development, and lymphoid organogenesis, and includes the components NF- $\mathrm{KB}$ (RelA/p65), NF- $\mathrm{BB} 1$ (p105/p50), NF-kB2 (p100/p52), RelB, and c-Rel [82]. $\mathrm{NF}-\mathrm{kB}$ signaling is activated by various extracellular ligands and their receptors-e.g., tumor necrosis factor

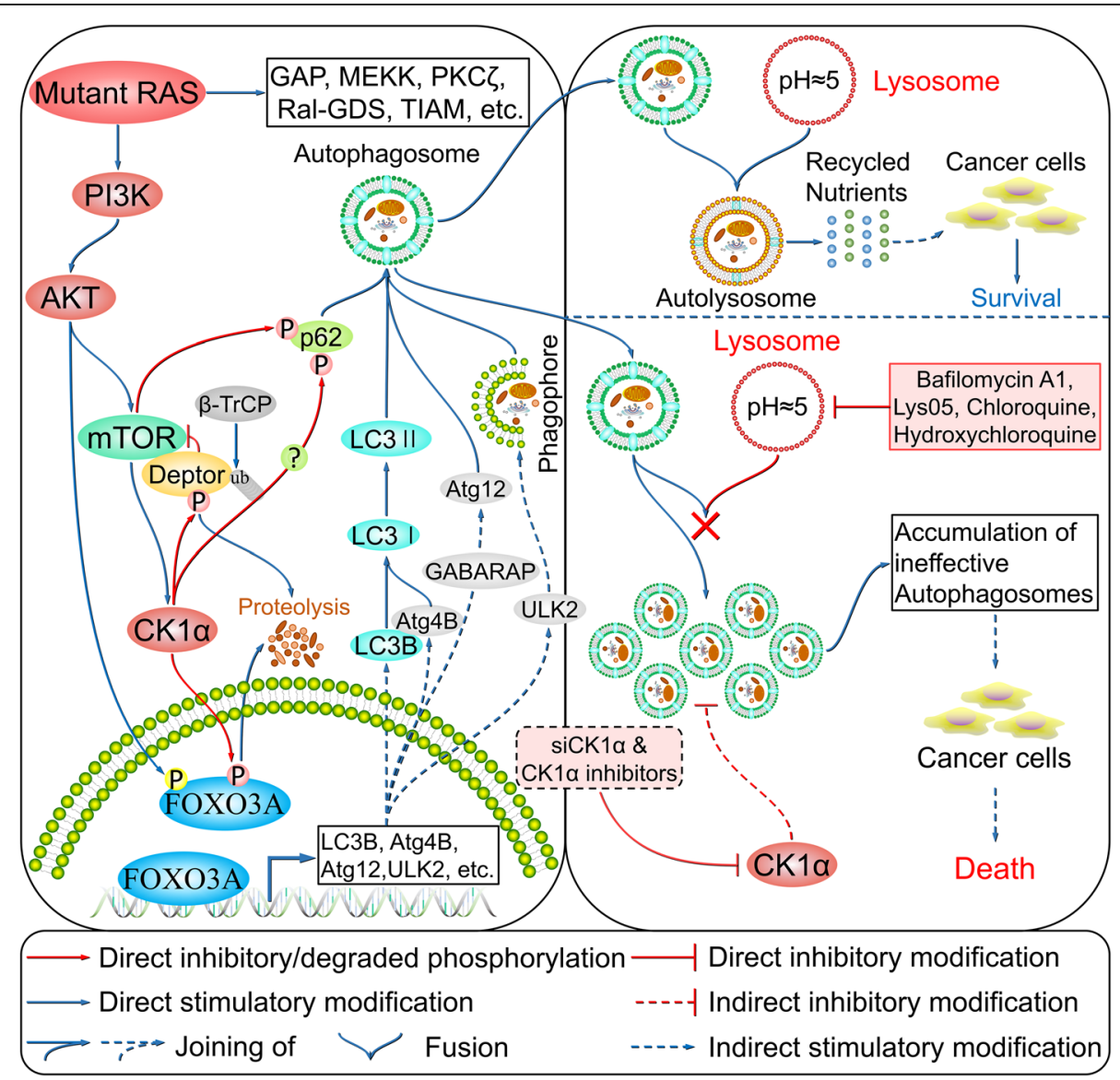

Fig. 6 Regulation of autophagy by CK1a. (also reviewed in references [54, 72]) 
receptor (TNFR), interleukin (IL)-1 receptor, Toll-like receptors, $B$ cell receptor $(\mathrm{BCR})$, and TCR. This activates the inhibitor of $\kappa B$ kinase (IKK) complex (IKK $\alpha$, IKK $\beta$, IKK $\gamma / \mathrm{NF}-$ kappa-B essential modulator), which phosphorylates inhibitor of $\kappa \mathrm{Bs}$ (I $\mathrm{KBs}$ ) and targets them for ubiquitination and proteasomal degradation. The free NF- $\mathrm{kB} /$ Rel complex is then modified by a series of kinases and translocated to the nucleus, where its activation alone or in combination with other transcription factors induces the expression of target genes.

TNF- $\alpha$ is a pro-inflammatory cytokine that activates two distinct cell surface receptors-namely, TNFR1 (p55) and TNFR2 (p75). CK1 $\alpha$ binds to and phosphorylates TNFR1 and TNFR2, which negatively regulate $\mathrm{TNF}-\alpha-$-mediated NF- $\mathrm{KB}$ activation $[83,84]$. Receptor-interacting serine/threonine kinase 1 (RIP1) is a critical factor in programmed necrosis, but also mediates TNF- $\alpha$ activation of NF- $\kappa B$ [85]. However, RIP1 is phosphorylated by CK1 $\alpha$ at amino acids 293558 , which potentiates TNF- $\alpha$-mediated NF- $\mathrm{KB}$ activation [83]. These two opposing activities suggest that NF- $\kappa B$ signaling regulates $C K 1 \alpha$, which also exhibits dual functions in immunoregulation. Fas-associated death domain (FADD) is an adaptor protein that transmits apoptotic signals through death receptors; it directly binds to RIP1, and mediates both necrosis and NF- $\mathrm{KB}$ activation. CK1 $\alpha$ phosphorylates FADD at Ser194 $[80,86]$, which is essential for NF- $\kappa B$ activation [87]. The caspase recruitment domain family member 11 (CARD11)/B-cell chronic lymphocytic leukemia/ lymphoma 10 (BCL10)/mucosa-associated lymphoid tissue lymphoma translocation gene 1 (MALT1) (CBM) signalosome complex functions as an adaptor to activate IKKs in antigen-receptor-induced NF- $\mathrm{kB}$ activation. Notably, CK1 $\alpha$ has been shown to directly bind to the CBM complex leading to NF- $\mathrm{KB}$ activation in response to TCR stimulation in normal lymphocytes, which largely depends on the association of phosphorylated BCL10 and ubiquitinated MALT1 with CK1 $\alpha$. Inhibitory phosphorylation of caspase recruitment domain-containing membrane-associated guanylate kinase protein 1 at Ser608 by CK $1 \alpha$ impairs its ability to activate NF- $\mathrm{kB}$. Activated B cell-like subtype of diffuse large B-cell lymphoma (ABC DLBCL) cells require $\mathrm{CK} 1 \alpha$ for constitutive NF-KB activity $[11,88]$; additionally, the oncoprotein $\mathrm{Y}$ box-binding protein 1 is phosphorylated by $\mathrm{CK} 1 \alpha$ at Ser176, resulting in NF- $\mathrm{kB}$ activation [89]. These findings provide evidence that $\mathrm{CK} 1 \alpha$ has dual functions in NF- $\mathrm{B}$ signaling (Fig. 7 and Table 1).

\section{CK1a in cell cycle regulation}

The mammalian cell cycle is a highly organized and regulated process initiated by mitogenic, growth, or survival signals [90] that activate downstream signaling pathways including mitogen-activated protein kinase signaling and induce the transcription of early-response genes including Myc, activator protein 1, $\beta$-catenin, c-Fos, and c-Jun. These in turn activate the expression of delayed-response genes including E2F1, cyclin D-cyclin-dependent kinase 4/ 6 (CDK4/6, also known as G1-CDK) complex, and cyclin E-CDK2 (also known as G1/S-CDK) complex. Cell division cycle 25 homolog A (CDC25A) potentiates the activity of G1- and G1/S-CDK to promote G1-S transition; G1/S-CDK then inactivates cyclin-dependent-kinase inhibitors (CKIs) by phosphorylation and removes the inhibition of the cyclin A-CDK2 complex (also known as $\mathrm{S}$-CDK). The pre-replication complex is phosphorylated by S-CDK and dissociates to ensure duplication of genetic material and cell division. During G2 phase, the multi-vulval class B (MUVB) complex associates with forkhead box M1 (FOXM1), which binds to promoters containing a cell cycle genes homology region (CHR). This induces the transcription of genes required for G2-M cell cycle transition such as cyclin B-CDK1 (also known as M-CDK), which is activated by $\mathrm{CDC} 25$ family members that dephosphorylate Thr14 and Tyr15 via membrane-associated tyrosine/ threonine 1 (MYT1, also known as PKMYT1) and WEE1, respectively. Meanwhile, CDK1 is phosphorylated at Thr161 by the cyclin H-CDK7 complex, leading to $M$ phase entry.

CK1 $\alpha$ exhibits cell cycle-dependent subcellular localization, including association with cytosolic vesicles and the nucleus during interphase and with the spindle during mitosis [20,21, 91]. As stated above, $\beta$-catenin is a substrate of $C K 1 \alpha$, and early-response genes including Myc and c-Jun are targets of $\mathrm{Wnt} / \beta$-catenin signaling. CK1 $\alpha$ also phosphorylates CDC25A at Ser79 and Ser82, which stimulates the binding of $\beta$-TrCP for subsequent ubiquitin-mediated proteolysis [92, 93]. Additionally, c-myc is phosphorylated by CK1 $\alpha$ at Ser252 through glioma pathogenesis-related protein 1 (GLIPR1) regulation, which is critical for its degradation [94]. Thus, CK1 $\alpha$ functions as a negative regulator in the early stages of the G1-S transition.

MDM2 and MDM4 together inhibit DNA binding and transcriptional activation of p53. Inhibition or knockdown of CK1 $\alpha$ was shown to increase p53, MDM2, and p21 levels and lead to dephosphorylation of $R B$, an inhibitor of the G1-S transition [7]. It was later confirmed that treatment with D4476 triggered an increase in nuclear p53 protein level, although the upregulation of MDM2 was mainly cytoplasmic rather than nuclear [95]. This implies that CK1 $\alpha$ interacts with MDM2 to stimulate its binding to $\mathrm{p} 53$, leading to ubiquitination and degradation of the latter. Moreover, MDMX is phosphorylated by CK1 $\alpha$ at Ser289, which is necessary for 


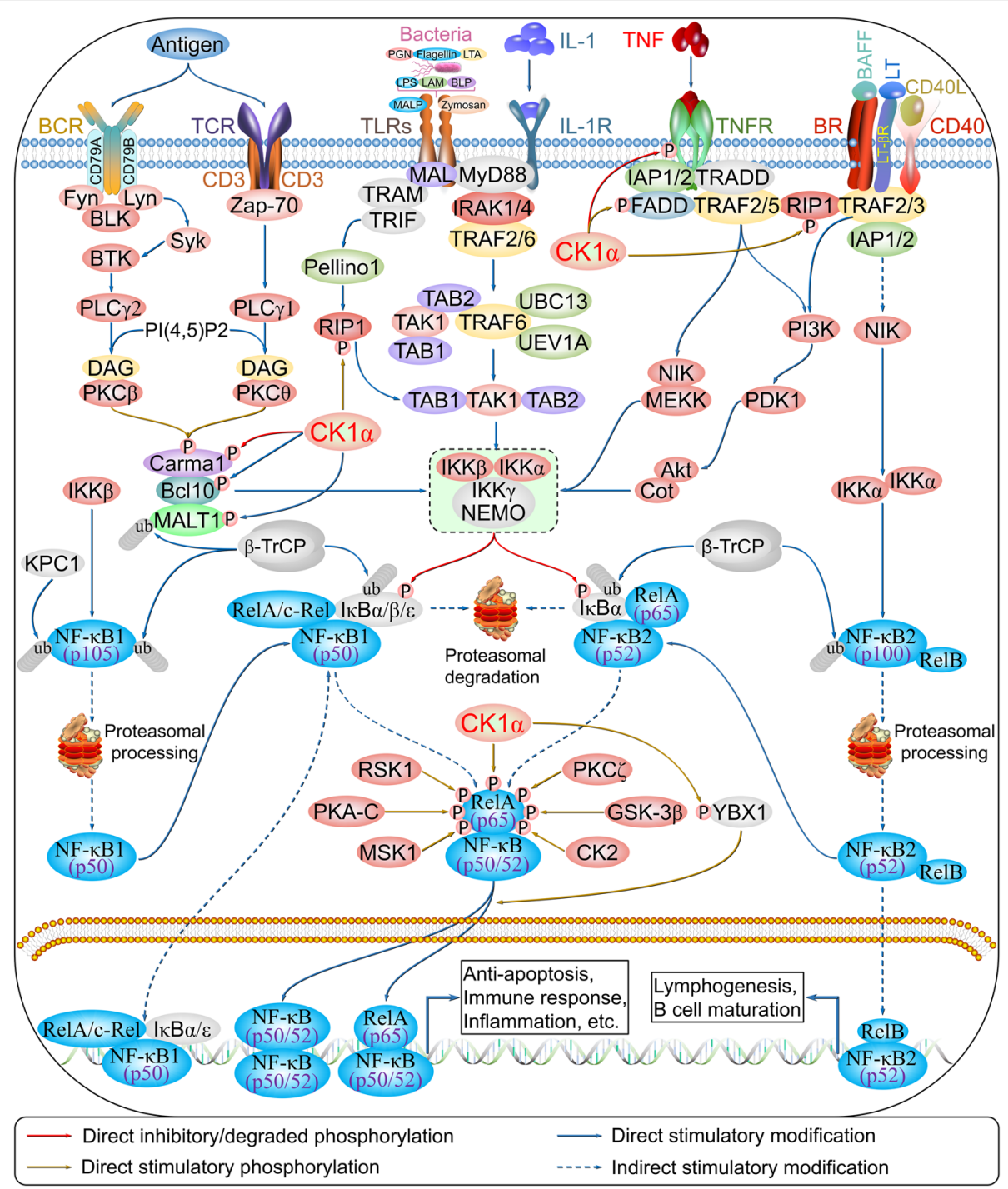

Fig. 7 Regulation of NF-KB signaling by CK1a. (also reviewed in references [253-257])

the MDMX-p53 interaction and inhibition of the DNA-binding and transcriptional activity of p53 [8, 9, 96]. Thus, CK1 $\alpha$ is a positive regulator of the G2-M transition. p53 is directly phosphorylated by CK1 $\alpha$ at Ser20 upon infection with human herpesvirus 6B viral [97]. Additionally, the Ser 20 residue of p53 is phosphorylated by checkpoint kinase $1 / 2$ in response to DNA damage, which enhances its tetramerization, stability, and activity $[98,99]$. To date, there is no in vivo or in vitro evidence for direct phosphorylation of p53 at Ser15 by CK1 $1 \alpha$; however, this is thought to occur through regulation of F-box and WD repeat domain-containing 7 (FBXW7), which influences the cell cycle and drug resistance [100]. CK1 $\alpha$ also phosphorylates $14-3-3 \tau$ and $14-3-3 \zeta$ at Ser23 and Thr233, respectively [101], thereby modulating their interaction with and nuclear exclusion of M-CDK (Fig. 8 and Table 1).
Jade- 1 phosphorylation by CK $1 \alpha$ and polo-like kinase 1 (PLK1) is an important biological event for cell cycle progression that involves phosphorylated FADD, which is most abundant during the G2/M phase. CK1 $\alpha$ colocalizes with its substrate FADD, which is phosphorylated at Ser194 in metaphase and early anaphase. Suppression of kinase activity by CKI-7 or siRNA-mediated CK1 $\alpha$ knockdown abrogates G2/M arrest induced by taxol $[80,86]$.

Less is known about the function of CK1 $\alpha$ in meiosis. CK1 $\alpha$ localizes to the spindle poles, which may not be required for meiotic progression in mammalian oocytes since RNA interference (RNAi) or overexpression of CK1 $\alpha$ results in invalid spindle organization and chromosome segregation [102]. CK1 $\alpha$ is activated in fertilized mouse oocytes but not in metaphase II-arrested mouse oocytes. Microinjection of a blocking 


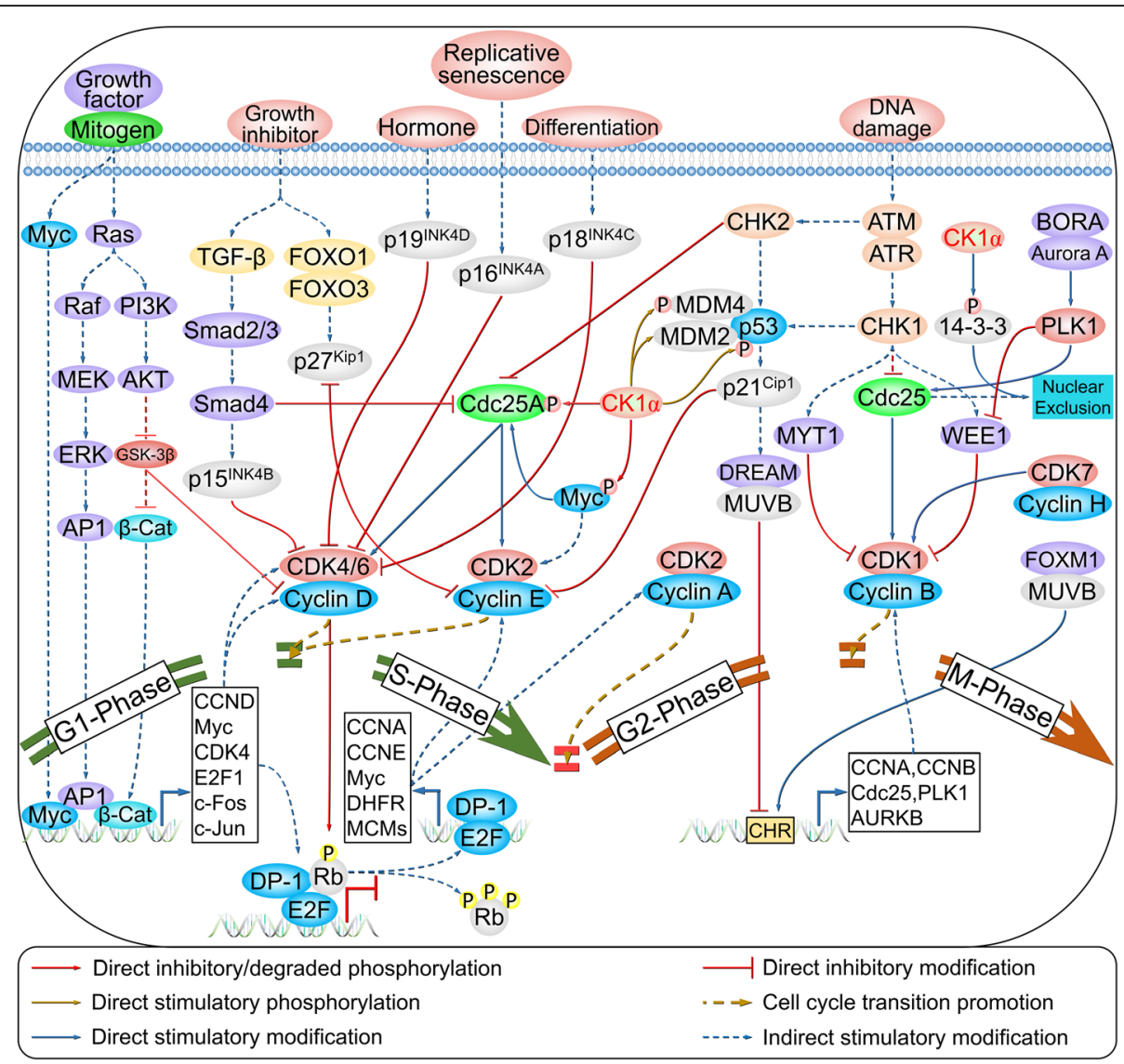

Fig. 8 Cell cycle regulation by CK1a. (also reviewed in reference [90])

antibody against CK1 $\alpha$ during metaphase II arrest and G2 phase had no effect on the completion of the second meiosis or first division; however, injection during the early pronuclear stage prior to $\mathrm{S}$ phase blocked kinase entry into pronuclei and interfered with timely cell cycle progression to the first cleavage [91]. However, another study showed that $\mathrm{CK} 1 \alpha$ was upregulated in metaphase and colocalized with condensed chromosomes during oocyte maturation and embryonic development; blocking CK1 $\alpha$ resulted in the failure of polar body 1 (PB1) extrusion, chromosome misalignment, and metaphase II plate incrassation, while activating CK1 $\alpha$ by pyrvinium pamoate treatment inhibited oocyte meiotic maturation and caused severe abnormalities in congression and chromosome misalignment [103].

Suppression of CK1 $\alpha$ in the gut triggers Wnt hyperactivation but does not lead to tumorigenesis, since the DNA damage response and cellular senescence are activated via induction of p53 and its downstream effector p21 [10]. Notably, CSNK1A1 deficiency caused hematopoietic stem cells (HSCs) to exit quiescence and re-enter the cell cycle; meanwhile, CSNK1A1 haploinsufficiency induced HSCs expansion and increased the S/G2/M-phase fractions, whereas homozygous deletion induced significant induction of early and late apoptosis and led to HSCs failure [104]. CK1 $\alpha$ loss was associated with cell cycle arrest in human colorectal polyps [105], and inhibition of CK1 $\alpha$ kinase activity in multiple myeloma cells by D4476 or siRNA treatment triggered G0/G1 arrest, prolonged $\mathrm{G} 2 / \mathrm{M}$ phase, and increased apoptosis [106]. These findings indicate that $\mathrm{CK} 1 \alpha$ has dual functions in cell cycle progression and cell division.

\section{CK1a in neurodegenerative diseases}

Alzheimer's disease (AD) is a progressive neurologic disease and leading cause of dementia that is characterized by the irreversible loss of neurons-particularly in the cortex and hippocampus [107]-leading to memory disorder, personality changes, and cognitive dysfunction [108]. Additional histopathological hallmarks include the presence of extracellular senile plaques containing the amyloid- $\beta$ (A $\beta$ ) peptides and neurofibrillary tangles (NFTs) [107].

$A \beta$ peptides are generated by the sequential cleavage of $A \beta$ precursor protein (APP). In a normal state, the $A \beta$ domain of APP is cleaved by $\alpha$-secretases (mainly A disintegrase and metalloprotease 10 [ADAM10]), releasing 
soluble $\mathrm{N}$-terminal (s)APP $\alpha$ and $\mathrm{C}$-terminal fragment $\alpha$ $(\mathrm{CTF} \alpha)$. The latter is cleaved by the $\gamma$-secretase complex composed of catalytic presenilin 1/2 (PS1/2), nicastrin (NCT), PS enhancer 2 (PEN2), and anterior pharynx defective $1 / 2$ (APH1/2), yielding a soluble extracellular p3 peptide and the APP intracellular domain (AICD). When the amyloidogenic pathway is activated in $A D$, APP is cleaved by $\beta$-secretase $1 / 2$, which releases the ectodomains sAPP $\beta$ and CTF $\beta$; subsequent cleavage of CTF $\alpha$ by $\gamma$-secretase yields A $\beta$ and AICD $[109,110]$. CK1 isoforms are upregulated in the brain of AD patients $[111,112]$ and directly phosphorylate $\beta$-secretase at Ser498, thereby regulating trafficking of $\beta$-secretase in the secretory and endocytic pathways [113]. Calsenilin (CSEN) binds PS1/2, the catalytic core of $\gamma$-secretase complex, and regulates its APP cleavage activity [114]; it is primarily phosphorylated at Ser63 by CK1, which protects it from cleavage by caspase 3 between Asp61 and Asp64 and generates an $\sim 28-\mathrm{kDa}$ C-terminal fragment. Thus, upregulation of CK1 may underlie AD pathology by modulating the phosphorylation state of AD-related proteins [115]. In addition, the sAPP $\beta$ ectodomain is phosphorylated by CK1 at Ser206 during secretory cleavage [116], while $A \beta$ in turn stimulates the kinase activity of CK1 [117].

NFTs are another characteristic of AD. In the normal state, tau is dephosphorylated and binds microtubules; hyperphosphorylation by CDK5 and GSK-3 $\beta$ inhibits its microtubule-binding capacity, resulting in the release of tau from axonal microtubules into the cytosol, with a consequent reduction in its solubility and microtubule destabilization [109, 118]. Tau oligomerization leads to the formation of NFTs and neuronal apoptosis [119]. CK1 isoforms also contribute to the hyperphosphorylation of tau, leading to its conversion to an abnormal AD-like state [120]. CK1 $\alpha$ was found to be closely associated with paired helical filaments (PHFs) purified from the brain tissue of $\mathrm{AD}$ patients. Thus, CK1 $\alpha$ is one of the major kinases responsible for the pathological hyperphosphorylation of tau protein [121].

Parkinson's disease (PD) is the second most common late-onset neurodegenerative disease after $A D$ and is characterized by an accumulation of $\alpha$-synuclein-also known as Parkinson disease protein 1 (PARK1) - and mitochondrial dysfunction [122] as well as bradykinesia, rigidity, and tremor due to the loss of dopaminergic neurons in the substantia nigra [123]. Other pathological hallmarks include progressive neuronal loss in a subset of brainstem and mesencephalic nuclei and aggregation of $\alpha$-synuclein in the form of Lewy bodies and neurites [124].

$\alpha$-Synuclein phosphorylated at Ser87 and especially Ser129 is the predominant form of the protein in Lewy bodies [125]. CK1s (mainly CK1 $\alpha$ ) and CK2 phosphorylate $\alpha$-synuclein at both residues [126, 127]. CREB, a transcription factor that induces the expression of peroxisome proliferator-activated receptor gamma coactivator- $1 \alpha$ $(\mathrm{PGC}-1 \alpha)$ and confers protection to dopaminergic neurons, is also phosphorylated by CK1 $\alpha$ at Ser108/111/114 [128], which may be critical for CRE-mediated gene expression induced by dopamine and calcium [129].

Mutations in PARK proteins (PARK1-PARK8)-especially $\alpha$-synuclein, Parkin (also known as PARK2), phosphatase and tensin homolog-induced putative kinase 1 (PARK6), DJ-1 (also known as PARK7), and leucine-rich repeat kinase 2 (LRRK2) (also known as PARK8)-have been detected in both familial and sporadic PD [107, 130]. LRRK2 is phosphorylated by CK1 $\alpha$ at Ser910/935/ 955/973 [131], whereas Parkin is phosphorylated by CK1 at Ser101/378 under okadaic acid treatment [132].

CDK5 is implicated in both AD and PD [133]. CDK5 is phosphorylated by CK1 $\delta$ at Ser159 [134], whereas p35-the catalytic and regulatory subunit of CDK5-is phosphorylated by CK1 $\alpha$. Additionally, CK1 $\alpha$ controls metabotropic glutamate receptor (mGluR)-mediated $\mathrm{Ca}^{2+}$ currents in the CK1 $\alpha / \mathrm{CDK} 5 /$ dopamine- and cAMP-regulated neuronal phosphoprotein 32 cascade [135]. A recent genome-wide analysis identified CSNK1A1 as a gene linked to language impairment [136]. Thus, CK1 $\alpha$ plays an important role in the pathogenesis of $\mathrm{AD}$ and $\mathrm{PD}$ (Fig. 9 and Table 1).

\section{CK1a in the host defense response}

In addition to NF- $\mathrm{KB}$ signaling, $\mathrm{CK} 1 \alpha$ is also involved in the host defense response against infectious pathogens. CK $1 \alpha$ phosphorylates type I interferon receptor 1 (IFNAR1) at Ser535 and thereby induces its ubiquitination and degradation via recruitment of $\beta$-TrCP E3 ubiquitin ligase in response to endoplasmic reticulum stress as well as infection $[137,138]$ by the protozoan Leishmania major or vesicular stomatitis virus (VSV) in human cells [137] and by infectious bursal disease virus in chicken [139]. Newly research have demonstrated that CK $1 \alpha$ mediates degradation of IFNAR1 and type II IFN (IFN- $\gamma)$ receptor 1 (IFNGR1) caused by hemagglutinin of influenza A virus (IAV) [140]. CK1 $\alpha$ also acts as a specific host factor and is required for the spread of Listeria monocytogenes between cells, which occurs via formation of productive membrane protrusions [141]. In Toxoplasma gondii, CK1 $\alpha$ is essential for replication in host cells; loss of CK1 $\alpha$ enhances the virulence of $T$. gondii in mice via upregulation of rhoptry proteins (ROPs), activation of signal transducer and activator of transcription 3, and suppression of IL-12 production [142].

CK1 $\alpha$ phosphorylates rotavirus non-structural protein 5 at Ser67 [143]; the hyperphosphorylated form of the 


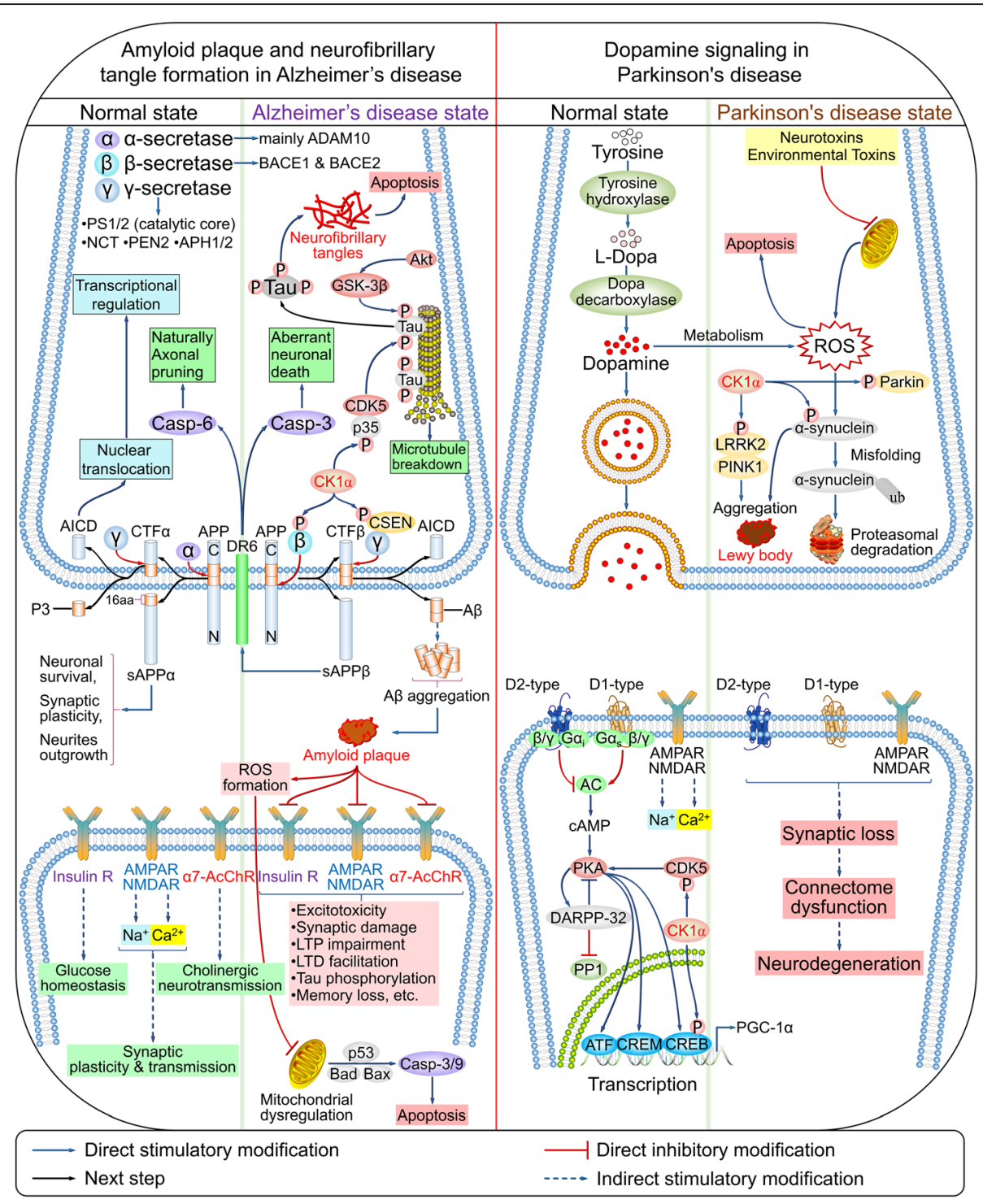

Fig. 9 Signaling pathways regulated by CK1a in neurodegenerative diseases. (also reviewed in references [109, 110, 118, 124, 258, 259])

protein is required for rotavirus RNA replication [144]. Similarly, CK1 $\alpha$ phosphorylates non-structural protein 5A (NS5A) of hepatitis C virus (HCV) at Ser232 and NS5 of yellow fever virus (YFV) at Ser56, leading to hyperphosphorylation of NS5A [145, 146] and NS5 [147] for RNA replication. Thus, CK1 $\alpha$ is required for pathogen infection, and specifically for viral RNA replication (Table 2).

\section{CK1a in cancer}

CK1 $\alpha$ is a component of the $\mathrm{Wnt} / \beta$-catenin signaling pathway that functions as a tumor suppressor [148]. Low levels of CSNK1A1 may contribute to tumorigenesis and poor prognosis, especially in colorectal cancer according to the data from open-source databases. However, nearest research reported that CSNK1A1 overexpression correlates with poor survival in colorectal cancer [149]. The opposite conclusions both lack the protein data. Notably, the $P$ value of overall survival calculated by Kaplan-Meier method that divided according to relative CSNK1A1 RNA expression in tumor tissue are both very close to 0.05 . Thus, the opposite conclusions need a large sample approach based on protein data for final verdict. CK1 $\alpha$ interacts with MDMX to inhibit the DNA-binding and transcriptional activity of p53 $[8,9,96]$, resulting in p53 ubiquitination and degradation via interaction with MDM2 [7]. CSNK1A1 was unrelated to the survival of sporadic colon cancer patients with functional p53, but those with low CSNK1A1 expression had very poor prognosis compared to patients with high CSNK1A1 levels and non-functional p53 [150]. Loss of CK1 $\alpha$ does not lead to 
Table 2 Substrates of human CK1a in various biological events

\begin{tabular}{lllll}
\hline Gene & Protein & Phosphorylation site & Function & Reference \\
\hline IFNAR1 & IFNAR1 & S535 & Leishmania majorNSV/ IAV & {$[137,138,140]$} \\
IFNGR1 & IFNGR1 & N/A & IAV & {$[140]$} \\
NS5A & NS5A & S232 & HCV & YFV \\
NS5 & NS5 & S56 & Rotavirus & {$[145,146]$} \\
NSP5 & NSP5 & S67 & mRNA metabolism & {$[143,144]$} \\
HNRNPC & hnRNP C1/C2 & S240/253, S247/260, S286/S299 & & {$[183]$} \\
TUT1 & Star-PAP, RBM21 & S6 & MiRNA-mediated silencing of target mRNA & {$[185]$} \\
AGO2 & AGO2 & S824, S828, T830, S831, S834 & Glioblastoma & {$[173]$} \\
KDM1A & LSD1 & S687 & Colorectal cancer & {$[166]$} \\
PHLPP1 & PHLPP1 & S1359, T1363, S1379, S1381 & Cancer metastasis & {$[174]$} \\
RAPGEF2 & RAPGEF2 & S1244, S1248 & Cancer apoptosis & {$[175]$} \\
RXRA & RXRa & N/A & & {$[176]$} \\
Bid & Bid & N/A & &
\end{tabular}

colorectal cancer due to induction of p53, unless both p53 and CK $1 \alpha$ genes are deleted [10]. CK $1 \alpha$ ablation also leads to activation of the IFN signaling pathway, which prevents unlimited proliferation of intestinal epithelial cells even when $\beta$-catenin is constitutively active. Concurrent loss of CK1 $\alpha$ and IFNAR1 leads to intestinal hyperplasia, inhibition of apoptosis, and rapid and lethal loss of the intestinal barrier function [151]. Thus, CK1 $\alpha$ maintains a balance among Wnt/ $\beta$-catenin, p53, and IFN signaling. It is also implicated in RAS-driven cancers such as colon cancer-which depends on autophagy [72] - and acts as a negative regulator in prostate cancer [94], liposarcoma [152], and ultraviolet radiation-induced skin tumors [153].

CSNK1A1 is located on chromosome $5 \mathrm{q} 32$ and is downregulated [154] or mutated $[155,156]$ in patients with in MDS del(5q). CSNK1A1 mutations have also been detected in adult $\mathrm{T}$ cell leukemia/lymphoma (ATL) [157], clear cell renal cell carcinoma [158], colon cancer [159], and esophageal adenocarcinoma [160, 161]. Haploinsufficiency of CSNK1A1 leads to $\beta$-catenin activation and expansion of the HSC pool, whereas homozygous deletion leads to inhibition of HSC proliferation [104]. The observation that over $50 \%$ of patients treated with lenalidomide experienced remission [162-164] was attributable to the fact that CSNK1A1 haploinsufficiency heightens sensitivity to the effects of lenalidomide-induced $\mathrm{CK} 1 \alpha$ degradation [12], which was shown to be mediated by valosin-containing protein (VCP)/p97 [165].

CK1 $\alpha$ phosphorylates pleckstrin homology domain leucine-rich repeat protein phosphatase 1 (PHLPP1) at Ser1359, Thr1363, Ser1379, and Ser1381 leading to its ubiquitination and degradation, which may promote colon cancer progression [166]. It also interacts with hematopoietic pre-B cell leukemia transcription factor-interacting protein (HPIP) to stimulate renal cell carcinoma growth and metastasis via activation of mTOR signaling [167]. CK1 $\alpha$ is more highly expressed in and can serve as a diagnostic marker for malignant melanoma [168]; however, CK1 $\alpha$ suppression in melanoma cells causes a switch in $\beta$-catenin signaling to promote metastasis $[169,170]$. It is also highly expressed in multiple myeloma and plasma cell leukemia [171], and has an oncogenic role in these malignancies. Likewise, $A B C$ DLBCL requires $C K 1 \alpha$ for constitutive NF- $\mathrm{K} B$ activity and survival; lenalidomide may have therapeutic effects in ABC DLBCL by inducing the degradation of CK1 $\alpha[11,12,172]$, as well as in pancreatic cancer in which CK1 $\alpha$ is upregulated. The current evidence suggests that CK1 $\alpha$ dependency resembles non-oncogenic addiction in which the cancer cell phenotype depends on hyperactivation of specific genes including NF-KB [11].

GSK-3 $\beta$ phosphorylates lysine-specific histone demethylase 1A (KDM1A, also known as LSD1) at Ser683 after priming phosphorylation at Ser687 by CK1 $\alpha$. This leads to KDM1A deubiquitination by ubiquitin-specific protease 22 (USP22) and subsequent stabilization, which is essential for glioblastoma development [173]. IKK $\beta$ stimulates the CK $1 \alpha$-mediated degradation of Rap guanine exchange factor 2 (RAPGEF2) via phosphorylation at Ser1244 and Ser1248 in response to hepatocyte growth factor (HGF), and may promote the dissemination and metastasis of human breast cancer cells [174].

CK1 $\alpha$ interacts with retinoid $\mathrm{X}$ receptor $\alpha(\mathrm{RXR} \alpha)$ and enhances cell survival by preventing RXR agonist-induced apoptosis in cancer cells [175]. CK1 $\alpha$ exerts an anti-apoptotic function by phosphorylating 
and preventing the caspase- 8 dependent cleavage of BH3-interacting domain death agonist (Bid) in HeLa cells [176] (Table 2).

CK1 $\alpha$ has also been implicated in lung [80, 148, 177179], breast [180], esophageal [181], and urothelial [182] cancers. It was found to promote KRASG12D-induced lung cancer through phosphorylation of FADD at Ser194 [80]; CK1 $\alpha$ inhibition prevented acquired drug resistance to erlotinib in epidermal growth factor receptor-mutant NSCLC [179]. On the other hand, the Ki-67-interacting protein Nucleolar protein interacting with the FHA domain of pKi-67 (NIFK) enhanced Ki-67-dependent cell migration and invasion in vitro and metastasis in vivo by reducing CK1 $\alpha$ level in lung cancer [148]. Thus, $\mathrm{CK} 1 \alpha$ is a potential therapeutic target due to its role as a conditionally essential malignancy protein.

\section{CK1a in other biological events}

The regulation of mRNA metabolism by CK1 $\alpha$ is evidenced by its localization at nuclear speckles and roles in the modification of small nuclear ribonucleoprotein particles (snRNPs) [22] and phosphorylation of heterogeneous nuclear ribonucleoprotein $\mathrm{C} 1 / \mathrm{C} 2$ (hnRNP $\mathrm{C} 1 /$ C2) - a nuclear-restricted pre-mRNA-binding proteinat Ser240/253, Ser247/260, and Ser-286/S299, which modulates its mRNA-binding capacity [183]. CK1 $\alpha$ phosphorylates speckle-targeted phosphatidylinositol-4, 5-biphosphate K1A-regulated poly(A) polymerase at Ser6 and induces the transcription of hemeoxygenase 1 $(\mathrm{HO}-1)$ and $\mathrm{NAD}(\mathrm{P}) \mathrm{H}$ quinone dehydrogenase 1 (NQO1) [184]. It was also shown to phosphorylate argonaute 2 (AGO2) at Ser824-Ser834 (mainly at Ser828), thereby preventing AGO2-associated target mRNA binding and attenuating micro (mi)RNA-mediated gene silencing [185]. Systems biology approaches have also identified CK $1 \alpha$ as a regulator of the DNA damage response in embryonic stem cells [186].

$\mathrm{CK} 1 \alpha$-mediated $\mathrm{Wnt} / \beta$-catenin signaling is essential for ontogenesis and stem cell fate determination [187]; for instance, its ablation causes the naked cuticle phenotype in Drosophila [188]. Stromal cell derived factor $1 \alpha$ (SDF1 $\alpha)$ inhibits CK1 $\alpha$ and attenuates CK1 $\alpha$-mediated phosphorylation, destabilization, and degradation of $\beta$-catenin, which is important for c-kit+ cardiac stem/ progenitor cell (CSPCs) quiescence under normal conditions and for myocardial regeneration following stress or injury [189]. CK1 $\alpha$ suppression leads to Wnt activation and transforming growth factor $\beta /$ mothers against decapentaplegic homolog 2 inhibition, resulting in the conversion of epiblast stem cells into embryonic stem cells (ESCs) [190] and promoting the establishment and maintenance of the pluripotency network [191]. CK1 $\alpha$ directly phosphorylates protein arginine methyltransferase 1 (PRMT1) (mainly at Ser284/Thr285/Ser286/289) to suppress grainyhead-like transcription factor 3 (GRHL3)-mediated terminal differentiation and maintain somatic tissue in a state of self-renewal [192]. Additionally, competitive bone marrow repopulation assays have demonstrated that CK1 $\alpha$ is essential for long-term HSCs function [193].

Muscarinic acetylcholine receptors (mAChRs) including M1 [194] and M3 [195, 196] are G protein-coupled receptors (GPCRs) [197] that are phosphorylated by CK1 $\alpha$ in an agonist-dependent manner. Phosphorylation of adaptor protein 3 (AP3) by CK1 $\alpha$ is required for the efficient formation synaptic vesicles from endosomes [198]. CK1 $\alpha$-mediated phosphorylation stimulates the degradation of the clock protein period circadian regulator 1 (PER1), suggesting a function in circadian rhythm [199]. Mice with heterozygous and homozygous CK $1 \alpha$ mutations in the adipose lineage developed diabetes as a result of dysregulated glucose metabolism [200]. CK1 $\alpha$ also participates in the regulation of human erythrocyte apoptosis by modulating cytosolic $\mathrm{Ca}^{2+}$ activity [201], and promotes homolog pairing and genome organization by inducing the degradation of chromosome-associated protein $\mathrm{H} 2$ (Cap-H2) and limiting chromatin-bound Cap-H2 levels in Drosophila [202].

\section{Regulation of CK1a by endogenous factors}

CK1 $\alpha$ functions as a broad Ser/Thr kinase that regulates multiple biological processes (Tables 1 and 2) and is itself regulated by various factors. For example, the miRNA miR-155 binds to the 3 '-untranslated region (3'-UTR) of CK1 $\alpha$ mRNA, thereby enhancing Wnt/ $\beta$-catenin signaling and cyclin D1 expression and promoting liposarcoma cell growth [152]. MiR-155 is also upregulated in systemic and localized scleroderma and may contribute to disease etiology by repressing CK $1 \alpha$ and Src homology 2-containing inositol phosphatase 1 (SHIP-1) [203]. Similarly, miR-9-5p binds to the 3'-UTR of both CK1 $\alpha$ and GSK-3 $\beta$, which mediate the migration of mesenchymal stem cells (MSCs) via $\mathrm{Wnt} / \beta$-catenin signaling [204].

CK1 $\alpha$ regulation at the protein level mostly involves transport and subcellular localization, activation/inactivation, and degradation. As stated earlier, CK1 $\alpha$ is localized at nuclear speckles and regulates multiple aspects of mRNA metabolism [22, 183]. However, the mechanism underlying CK1 $\alpha$ nuclear transport was only recently elucidated: SON DNA-binding protein localizes to nuclear speckles and acts as a scaffold to which CK1 $\alpha$ is recruited by family with sequence similarity $83 \mathrm{mem}$ ber H (FAM83H) [205]. Additionally, GLIPR1-mediated redistribution of $\mathrm{CK} 1 \alpha$ from the Golgi apparatus to the cytoplasm as well increased CK1 $\alpha$ protein level is essential for $\beta$-catenin phosphorylation and destruction [94]. 
CK1 members were considered as rogue kinases because their enzymatic activity is apparently unregulated. Of note, RNA helicase DDX3 was identified as a binding protein of $\mathrm{CK} 1 \alpha$ which directly stimulates its kinase activity in a Wnt-dependent manner [206]. But no endogenous inhibitor of CK1 $\alpha$ has been identified to date, even the degradation of CK $1 \alpha$ is mediated by lenalidomide [12, 13, 207].

\section{Small molecules targeting CK1a}

Small molecules are the most useful research tools for investigating protein function, since the clinical application of RNAi and clustered regularly interspaced short palindromic repeats (CRISPR)/CRISPR-associated protein- 9 nuclease-mediated gene knockout-while attractive approaches-has numerous challenges or is unfeasible. CKI-7-the first CK1 inhibitor to be developed [208]-is now widely used, with a $50 \%$ inhibitory concentration (IC50) of 113$236 \mu \mathrm{M}[80,209,210]$. IC261 was originally used as a selective inhibitor of $\mathrm{CK} 1 \varepsilon / \delta$ [211], but has since been shown to block the activity of all CK1 isoforms, with an IC50 of $0.19 \mu \mathrm{M}$ for CK1 $\alpha$ [131, 212]. TG003 was originally identified as a cell division cycle-like kinase inhibitor [213] that suppresses $C K 1 \delta / \varepsilon$ activity to a degree equal to or greater than IC261 [214, 215], with an IC50 of $0.33 \mu \mathrm{M}$ for CK1 $\alpha$ [212]. D4476 is the most effective and widely used inhibitor of CK1s, with an IC50 of 200-300 nM [216]. Triamterene-a drug approved by the Food and Drug Administration of the United States (FDA) for the treatment of edematous disorders such as cardiac failure, nephrotic syndrome, and hepatic cirrhosis [217]—was shown to induce epiblast stem cell reprogramming by inhibiting CK1 $\alpha$, with an IC50 of $33.5 \mu \mathrm{M}$. However, it also suppressed the kinase activity of CK1 $\delta$ and CK $1 \varepsilon$, with IC50 values of 6.9 and $30.4 \mu \mathrm{M}$, respectively [190]. Epiblastin A is a triamterene analog that was developed for more potent inhibition of $\mathrm{CK} 1 \alpha$; the IC50 values for $\mathrm{CK} 1 \alpha, \mathrm{CK} 1 \delta$, and $\mathrm{CK} 1 \varepsilon$ are $3.8,0.8$, and $3.7 \mu \mathrm{M}$, respectively [190]. A high-throughput chemical screen identified longdaysin as a small molecule that directly binds CK1 $\alpha$ and blocks CK1 $\alpha$-mediated phosphorylation and degradation of PER1, inhibiting CK1 $\alpha$ and CK1 $\delta$ with IC50 values of 5.6 and $8.8 \mu \mathrm{M}$, respectively [199].

At present there are no inhibitors that selectively target CK $1 \alpha$ or other CK1 isoforms. Nonetheless, the available compounds have been used to study CK1 $\alpha$ function. For example, IC261 was used to inhibit CK1 $\alpha$ phosphorylation of LRRK2 at Ser935 [131]. In another study, IC261 could not block FADD phosphorylation of FADD at Ser194 by CK1 $\alpha$, although this was achieved by CKI-7 and D4476 [86].
Lenalidomide is a thalidomide analog and FDA approved drug that does not inhibit $\mathrm{CK} 1 \alpha$ but induces CK1 $\alpha$ ubiquitination and degradation via CRL4CRBN E3 ubiquitin ligase at concentrations of $0.1-10 \mu \mathrm{M}$ [12], which has been confirmed by structural analyses [13].

Pyrvinium is an FDA-approved antihelminthic drug that has now been replaced by a more effective, broad-spectrum alternative, although it is still available under the Parke-Davis label in Europe and under the name pamoxan (Sato Pharmaceutical, Tokyo) in Japan [218]. Pyrvinium is a potent inhibitor of Wnt signaling that potentiates the kinase activity of $\mathrm{CK} 1 \alpha$ and stabilizes Axin [51]. Oral administration of pyrvinium was shown to attenuate the expression of Wnt signaling targets and prevent adenoma formation in $\mathrm{APC}^{\mathrm{min}}$ mice [219], in addition to stimulating wound repair and myocardial remodeling [220]. Remarkably, subsequent study indicated that pyrvinium did not activates $\mathrm{CK} 1 \alpha$, but activated GSK3 and down-regulated Akt signaling pathway. However, the study lacks the evidence such as direct interaction between pyrvinium and GSK3 or Akt [221]. SSTC-104 is a functional analog of pyrvinium that activates $C K 1 \alpha$, and may be able to counter aberrant Wnt/ $\beta$-catenin activation by synovial sarcoma (SS) translocation-SSX (also known as SS18-SSX) fusion protein [222]. Later studies reported that poor bioavailability limited the applicability of pyrvinium, and the new CK1 $\alpha$ activator SSTC3-which has better pharmacokinetic properties-was developed [223, 224] (Fig. 10). Interestingly, the histone deacetylase 6 inhibitor ACY-1215 was shown to increase Lys49 acetylation and Ser45 phosphorylation by CK1 $\alpha$ without affecting Ser33/ 37 and Thr-41 phosphorylation by GSK-3 $\beta$ [225].

\section{Conclusions}

Human $C K 1 \alpha$ is an important protein implicated in colorectal cancer [10], MDS del(5q) [12, 13], ABC DLBCL [11], and neurodegenerative diseases [113, $126,128,132]$. However, there are many open questions regarding the physiological function of CK1 $\alpha$. Firstly, the mechanism of CK1 $\alpha$ regulation remains obscure. At the level of transcription, it is unknown whether the regulatory mechanism involves methylation/demethylation of the CSNK1A1 gene promoter. At the post-transcriptional level, a few miRNAs such as miR-155 and $-9-5 \mathrm{p}$ are known to negatively regulate the CSNK1A1 transcript [152, 203, 204]; however, it is possible that other as-yet unidentified non-coding (nc)RNAs including small nuclear RNAs (snRNAs), small nucleolar RNAs (snoRNAs), long ncRNAs (lncRNAs), and circular RNAs are also involved. CK $1 \alpha$ protein expression is controlled at the level of degradation [12, 13] and transport [205]. Although upregulation of $\mathrm{PIP}_{2}$ in the plasma 


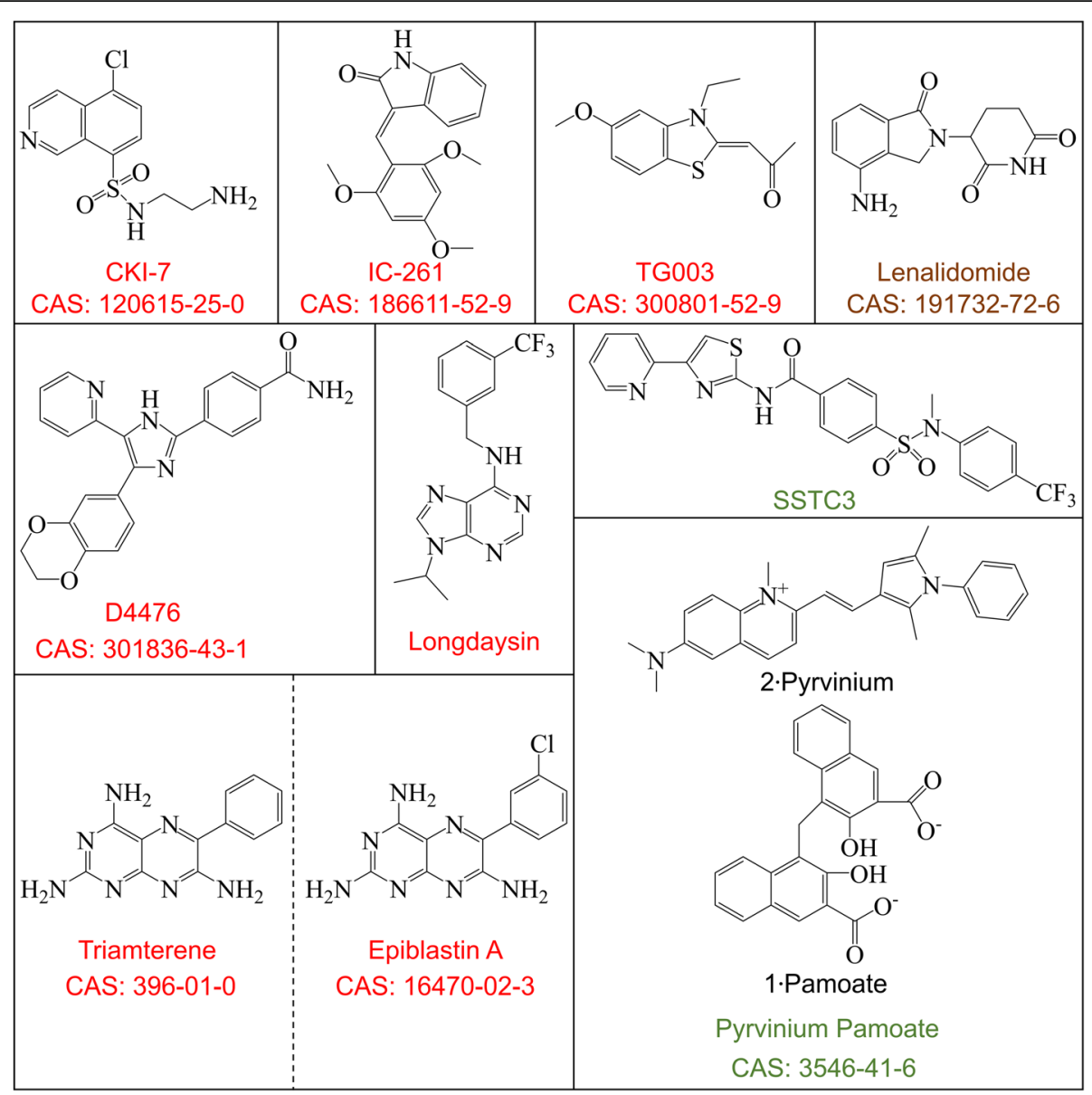

Fig. 10 Small molecule inhibitors and agonists of CK1a

membrane was shown to reduce $\mathrm{CK} 1 \alpha$ activity in erythrocytes and neuronal cells [20, 226-228], there is little known about the endogenous mechanisms of CK1 $\alpha$ activation/inactivation. As above mentioned, DDX3 directly stimulates the kinase activity of CK $1 \alpha$ in a Wnt-dependent manner [206]. A study of CK1 $\alpha$ isoforms in zebrafish (Danio rerio) suggested that the protein kinase activity of CK1 $1 \alpha$ depends on autophosphorylation of C-terminal residues [229]. Clarifying the mechanisms underlying the activation/inactivation of $\mathrm{CK} 1 \alpha$ in different contexts could provide a basis for designing highly targeted and more effective drugs.

CK1 $\alpha$ was recently reported that CK1 $1 \alpha$ participates in p53-dependent paracrine factor secretion in skin hyperpigmentation [230]. Future studies will likely provide additional evidence of a role for CK $1 \alpha$ in secretion. In addition, downregulation of CK1 $\alpha$ in lung cancer, which induced by NIFK is associated with worse prognosis possibly due to activation of $\mathrm{Wnt} / \beta$-catenin signaling and stimulation of tumorigenesis [148]. On the other hand, the overexpression of CK $1 \alpha$ in other malignancies such as pancreatic cancer has also been linked to poor outcome. Whether CK1 $\alpha$ induces constitutive activation of NF- $\mathrm{kB}$ in pancreatic cancer as in the case of $\mathrm{ABC}$ DLBCL, and how it maintains a balance between Wnt/ $\beta$-catenin, NF- $\kappa B$, and other signaling pathways remains to be determined.

Splice variants (isoforms) of CK1 $\alpha$ have been identified in cell/animal models such as chicken [231], rat [232] and human [233]. All isoforms of CK1 $\alpha$ have CK1 catalytic properties, but exhibit different binding activity toward common CK1 substrates [232]. The different isoforms of human CK1 $\alpha$ have variable amino acid sequences and distinct functions. CK1 $\alpha$ isoform 1 with an NLS in the 28-amino-acid "L" insert (CK1 $\alpha \mathrm{LS})$-but not isoforms 2-4-regulates nuclear signaling in response to $\mathrm{H}_{2} \mathrm{O}_{2}$ [14]. CK1 $\alpha \mathrm{LS}$ also promotes vascular cell proliferation and intimal hyperplasia [234], and mediates the effects of NADPH oxidase on vascular activation [235]. The 12-amino-acid " $\mathrm{S}$ " insert near the $\mathrm{C}$ terminus may function as a kinase domain for $\mathrm{CK} 1 \alpha$ in zebrafish [229]. A phosphoproteome analysis revealed that isoform 2 of $\mathrm{CK} 1 \alpha$ is phosphorylated at Thr321 
[236], which may be linked to endogenous activation/ inactivation of CK1 $\alpha$.

$\operatorname{Del}(5 \mathrm{q})$ can be detected in not only MDS but also acute lymphoblastic leukemia, especially at $5 \mathrm{q} 32$ where the CSNK1A1 gene exists [237]. Thus, CK1 $\alpha$ is an attractive molecular target for both diagnosis and monitoring therapy under the treatment of lenalidomide. CK1 $\alpha$ is a Ser/Thr kinase with a large number of substrates, some of which have yet to be experimentally verified using approaches such as a pull-down assay, protein interaction domain mapping, and point mutation. A combination of tandem affinity purification and mass spectrometry may facilitate the discovery of new substrates. Additionally, identifying or designing more effective and specific inhibitors, agonists and blocking peptides [95] should enable CK1 $\alpha$ targeting in a variety of clinical contexts. Application of small molecule library such as Pfizer compounds and molecular docking algorithm based on the structural information of CK1 $\alpha$ may be the most effective approaches so far. Once these inhibitors,agonists and blocking peptides are identified, development of therapy specifically targeting CK $1 \alpha$ should open the new avenues for effective management of a broad spectrum of diseases.

\section{Abbreviations}

3'-UTR: 3'-untranslated region; ABC DLBCL: Activated B cell-like subtype of diffuse large B-cell lymphoma; AD: Alzheimer's disease; ADAM10: A disintegrase and metalloprotease 10; AGO2: Argonaute 2; AICD: APP intracellular domain; AP3: Adaptor protein 3; APC: Adenomatous polyposis coli; APH1/2: Anterior pharynx defective 1/2; APP: $A \beta$ precursor protein; $A \beta$ : Amyloid- $\beta$; BCL10: $B$ cell chronic lymphocytic leukemia/lymphoma 10; BCR: B cell receptor; Bid: $\mathrm{BH} 3$-interacting domain death agonist; Brg-1: BRM/SWI2-related gene 1; Cap-H2: Chromosome-associated protein H2; CARD11: Caspase recruitment domain family member 11; CBM: CARD11/BCL10/MALT1; CBP: CREB binding protein; CDC25A: Cell division cycle 25 homolog A; CDK4/6: Cyclin D-cyclindependent kinase 4/6; CHR: Cell cycle genes homology region; CK1a: Casein kinase 1a; CKIs: Cyclin-dependent-kinase inhibitors; CRBN: Cullin 4/really interesting new gene-box 1/DNA damage-binding protein 1/cereblon (also known as CRL4 ${ }^{\text {CRBN }}$ ); CREB: (yclic (c)AMP response element-binding protein; CRISPR: Clustered regularly interspaced short palindromic repeats; CSEN: Calsenilin; CSPCs: Cardiac stem/progenitor cell; CTFa: C-terminal fragment a; DARRP-32: Dopamine- and CAMP-regulated neuronal phosphoprotein 32; DEPTOR: DEP domain-containing mTOR-interacting protein; ESCs: Embryonic stem cells; FADD: Fas-associated death domain; FAM83H: Family with sequence similarity 83 member H; FBXW7: F-box and WD repeat domain-containing 7; FOXM1: Forkhead box M1; FOXO3A: Forkhead box protein O3A; GABARAPs: Gamma-aminobutyric acid type A receptor-associated proteins; GLIPR1: Glioma pathogenesis-related protein 1; GPCRs: G protein-coupled receptors; GRHL3: Grainyhead-like transcription factor 3; GSK-3 $\beta$ : Glycogen synthase kinase $3 \beta$; HCV: Hepatitis C virus; HGF: Hepatocyte growth factor; hnRNP C1/C2: Heterogeneous nuclear ribonucleoprotein $\mathrm{C} 1 / \mathrm{C} 2$; HO-1: Hemeoxygenase 1; HPA: The human protein atlas; HSCs: Hematopoietic stem cells; IAV: Influenza A virus;

IFNAR1: Interferon receptor 1; IFNGR1: IFN- $\gamma$ receptor 1; IKK: Inhibitor of $\mathrm{KB}$ kinase; IKBs: Inhibitor of KBs (including IKBa, $\beta$, and $\varepsilon$ ); KDM1 A: Lysine-specific histone demethylase 1A (also known as LSD1); LC3-II: Microtubule-associated protein 1A/1B-light chain 3-II; IncRNA: Long non-coding RNA; LRP6: Lowdensity lipoprotein receptor-related protein 6; LRRK2: Leucine-rich repeat kinase 2; mAChRs: Muscarinic acetylcholine receptors; MALT1: Mucosaassociated lymphoid tissue lymphoma translocation gene 1; MDM2: Murine double minute clone 2; MDM4: Murine double minute clone 4 (also known as MDMX); MDS del(5q): Myelodysplastic syndrome with deletion of chromosome 5q; mGluR: Metabotropic glutamate receptor;
MSCs: Mesenchymal stem cells; mTOR: Mammalian target of rapamycin; MUVB: Multi-vulval class B; MYT1: Membrane-associated tyrosine/threonine 1 (also known as PKMYT1); NCT: Nicastrin; NEDD4-1: Neural precursor cell expressed: developmentally down-regulated 4-1; NFTs: Neurofibrillary tangles; NF-KB: Nuclear factor KB; NIFK: FHA domain of pKi-67; NLS: Nuclear localization signal; NQO1: NAD(P)H quinone dehydrogenase 1; NS5A: Nonstructural protein 5A; NSCLC: Non-small-cell lung cancer; PARK1: Parkinson disease protein 1; PB1: Polar body 1; PD: Parkinson's disease; PDB: Protein data bank; PEN2: PS enhancer 2; PER1: Period circadian regulator 1; PGC1a: Proliferator-activated receptor gamma coactivator-1a; PHFs: Paired helical filaments; PHLPP1: Pleckstrin homology domain leucine-rich repeat protein phosphatase 1; PI3K: Class III phosphatidylinositol-3 kinase; PLK1: polo-like kinase 1; PRMT1: Protein arginine methyltransferase 1; PS1/2: Presenilin 1/2; PTEN: Phosphatase and tensin homolog deleted on chromosome ten; RAPGEF2: Rap guanine exchange factor 2; RIP1: Receptor-interacting serine/ threonine kinase 1; RNAi: RNA interference; ROPs: Rhoptry proteins; RXRa: Retinoid X receptor a; SDF1a: Stromal cell derived factor 1a; SHIP1: Src homology 2-containing inositol phosphatase 1; Smo: Smoothened; snoRNA: Small nucleolar RNA; snRNA: Small nuclear RNA; snRNPs: Small nuclear ribonucleoprotein particles; SQSTM1: Sequestosome 1; TCGA: The cancer genome atlas; TCR: T cell receptor; ULK1/2: Unc-51-like autophagy activating kinase 1; USP22: Ubiquitin-specific protease 22; VCP: Valosincontaining protein; Vps15: Vacuolar protein sorting-associated protein 15; VSV: Vesicular stomatitis virus; WTX: Wilms tumor gene on X chromosome (also known as APC membrane recruitment protein 1); YFV: Yellow fever virus; $\beta$-TrCP: $\beta$-transducin repeat-containing E3 ubiquitin protein ligase

\section{Funding}

This study was supported by the National Key Basic Research Program (973 Program) (no. 2014CB744505 to X.Y.); Key Program of National Natural Science Foundation of China (no. 81430040 to X.Y.); General Program of National Natural Science Foundation of China (no. 81571738 to J.S.); National Key Research and Development Program of China (no. 2016YFA0100900 to J.S.); and Medical and Health Program of Zhejiang Province (nos. 2016146039 and 2017209189 to M.Z.).

\section{Authors' contributions}

Project planning was done by XY, SJ, and MZ; SJ, and MZ analyzed data and wrote a draft of the paper with the help of JS; XY conceived the ideas, designed the structure and content of review, supervised progress and extensively edited and communicated regarding the manuscript. All authors read and approved the final manuscript.

\section{Authors' information}

Corresponding author: Xiaoming Yang, MD, PhD. A principal investigator and an attending physician of radiology of Sir Run Run Shaw Hospital (an affiliated Hospital of Zhejiang University, School of Medicine), also a professor and director of image-guided bio-molecular interventions research in the Department of Radiology at the University of Washington School of Medicine, and holds an appointment as a senior lecturer of radiology at Kuopio University in Finland and as an attending physician of radiology qualified in interventional radiology at UW Medical Center and European community countries.

First author: Shaojie Jiang, MD, PhD. candidate. An MD/PhD candidate student of professor Xiaoming Yang in Zhejiang University.

Co-first author: Miaofeng Zhang, MD. A surgeon of Second Affiliated Hospital (an affiliated Hospital of Zhejiang University, School of Medicine).

Co-author: Jihong Sun, MD, PhD. An attending physician of radiology of Sir Run Run Shaw Hospital (an affiliated Hospital of Zhejiang University, School of Medicine).

Ethics approval and consent to participate Not applicable.

\section{Competing interests}

The authors declare that they have no competing interests.

\section{Publisher's Note}

Springer Nature remains neutral with regard to jurisdictional claims in published maps and institutional affiliations. 


\section{Author details}

'Department of Radiology, Sir Run Run Shaw Hospital, School of Medicine, Zhejiang University, Zhejiang 310016, Hangzhou, China. ${ }^{2}$ Department of Orthopaedics, Second Affiliated Hospital, School of Medicine, Zhejiang University, Zhejiang 310009, Hangzhou, China. ${ }^{3}$ Image-Guided Bio-Molecular Intervention Research, Department of Radiology, University of Washington School of Medicine, Seattle, WA 98109, USA.

\section{Received: 18 April 2018 Accepted: 16 May 2018}

\section{Published online: 24 May 2018}

\section{References}

1. Desjardins PR, Lue PF, Liew CC, Gornall AG. Purification and properties of rat liver nuclear protein kinases. Can J Biochem. 1972;50:1249-59.

2. Matsumura S, Takeda M. Phosphoprotein kinases from rat liver cytosol. Biochim Biophys Acta. 1972;289:237-41.

3. Hathaway GM, Traugh JA. Cyclic nucleotide-independent protein kinases from rabbit reticulocytes. Purification of casein kinases. J Biol Chem. 1979; 254:762-8.

4. Rowles J, Slaughter C, Moomaw C, Hsu J, Cobb MH. Purification of casein kinase I and isolation of cDNAs encoding multiple casein kinase I-like enzymes. Proc Natl Acad Sci U S A. 1991;88:9548-52.

5. Liu C, Li Y, Semenov M, Han C, Baeg GH, Tan Y, et al. Control of betacatenin phosphorylation/degradation by a dual-kinase mechanism. Cell. 2002;108:837-47.

6. Amit S, Hatzubai A, Birman Y, Andersen JS, Ben-Shushan E, Mann M, et al. Axin-mediated CKI phosphorylation of beta-catenin at Ser 45: a molecular switch for the Wnt pathway. Genes Dev. 2002;16:1066-76.

7. Huart AS, MacLaine NJ, Meek DW, Hupp TR. CK1alpha plays a central role in mediating MDM2 control of p53 and E2F-1 protein stability. J Biol Chem. 2009:284:32384-94

8. Wu S, Chen L, Becker A, Schonbrunn E, Chen J. Casein kinase 1alpha regulates an MDMX intramolecular interaction to stimulate p53 binding Mol Cell Biol. 2012;32:4821-32.

9. Wei X, Wu S, Song T, Chen L, Gao M, Borcherds W, et al. Secondary interaction between MDMX and p53 core domain inhibits p53 DNA binding. Proc Natl Acad Sci U S A. 2016;113:E2558-63.

10. Elyada E, Pribluda A, Goldstein RE, Morgenstern Y, Brachya G, Cojocaru G, et al. CKlalpha ablation highlights a critical role for p53 in invasiveness control. Nature. 2011:470:409-13.

11. Bidere N, Ngo VN, Lee J, Collins C, Zheng L, Wan F, et al. Casein kinase 1alpha governs antigen-receptor-induced NF-kappaB activation and human lymphoma cell survival. Nature. 2009;458:92-6.

12. Kronke J, Fink EC, Hollenbach PW, MacBeth KJ, Hurst SN, Udeshi ND, et al. Lenalidomide induces ubiquitination and degradation of CK1alpha in del(5q) MDS. Nature. 2015:523:183-8.

13. Petzold G, Fischer ES, Thoma NH. Structural basis of lenalidomide-induced CK1alpha degradation by the CRL4(CRBN) ubiquitin ligase. Nature. 2016;532: 127-30.

14. Bedri S, Cizek SM, Rastarhuyeva I, Stone JR. Regulation of protein kinase CK1alphaLS by dephosphorylation in response to hydrogen peroxide. Arch Biochem Biophys. 2007;466:242-9.

15. Fu Z, Chakraborti T, Morse S, Bennett GS, Shaw G. Four casein kinase I isoforms are differentially partitioned between nucleus and cytoplasm. Exp Cell Res. 2001;269:275-86.

16. Yang W, Garrett L, Feng D, Elliott G, Liu X, Wang N, et al. Wnt-induced Vangl2 phosphorylation is dose-dependently required for planar cell polarity in mammalian development. Cell Res. 2017;27:1466-84.

17. Bustos VH, Marin O, Meggio F, Cesaro L, Allende CC, Allende JE, et al. Generation of protein kinase Ck1alpha mutants which discriminate between canonical and non-canonical substrates. Biochem J. 2005;391:417-24.

18. Bustos $\mathrm{VH}$, Ferrarese $A$, Venerando A, Marin O, Allende JE, Pinna LA. The first armadillo repeat is involved in the recognition and regulation of betacatenin phosphorylation by protein kinase CK1. Proc Natl Acad Sci U S A. 2006;103:19725-30.

19. Dubois T, Howell S, Zemlickova E, Aitken A. Identification of casein kinase lalpha interacting protein partners. FEBS Lett. 2002;517:167-71.

20. Gross SD, Hoffman DP, Fisette PL, Baas P, Anderson RA. A phosphatidylinositol 4,5-bisphosphate-sensitive casein kinase I alpha associates with synaptic vesicles and phosphorylates a subset of vesicle proteins. J Cell Biol. 1995;130:711-24.
21. Brockman JL, Gross SD, Sussman MR, Anderson RA. Cell cycle-dependent localization of casein kinase I to mitotic spindles. Proc Natl Acad Sci U S A. 1992;89:9454-8

22. Gross SD, Loijens JC, Anderson RA. The casein kinase lalpha isoform is both physically positioned and functionally competent to regulate multiple events of mRNA metabolism. J Cell Sci. 1999;112(Pt 16):2647-56.

23. Gross SD, Anderson RA. Casein kinase I: spatial organization and positioning of a multifunctional protein kinase family. Cell Signal. 1998;10:699-711.

24. Kang DE, Soriano S, Xia X, Eberhart CG, De Strooper B, Zheng H, et al. Presenilin couples the paired phosphorylation of beta-catenin independent of axin: implications for beta-catenin activation in tumorigenesis. Cell. 2002; 110:751-62.

25. Sturgeon CM, Ditadi A, Awong G, Kennedy M, Keller G. Wnt signaling controls the specification of definitive and primitive hematopoiesis from human pluripotent stem cells. Nat Biotechnol. 2014;32:554-61.

26. Phelps RA, Chidester S, Dehghanizadeh S, Phelps J, Sandoval IT, Rai K, et al. A two-step model for colon adenoma initiation and progression caused by APC loss. Cell. 2009;137:623-34.

27. Benham-Pyle BW, Pruitt BL, Nelson WJ. Cell adhesion. Mechanical strain induces E-cadherin-dependent Yap1 and beta-catenin activation to drive cell cycle entry. Science. 2015:348:1024-7.

28. Major MB, Camp ND, Berndt JD, Yi X, Goldenberg SJ, Hubbert C, et al. Wilms tumor suppressor WTX negatively regulates WNT/beta-catenin signaling. Science. 2007;316:1043-6.

29. Wu X, Tu X, Joeng KS, Hilton MJ, Williams DA, Long F. Rac1 activation controls nuclear localization of beta-catenin during canonical Wnt signaling. Cell. 2008;133:340-53.

30. Nusse R, Clevers H. Wnt/beta-catenin signaling, disease, and emerging therapeutic modalities. Cell. 2017;169:985-99.

31. Ferrarese A, Marin O, Bustos VH, Venerando A, Antonelli M, Allende JE, et al. Chemical dissection of the APC repeat 3 multistep phosphorylation by the concerted action of protein kinases CK1 and GSK3. Biochemistry. 2007:46: 11902-10

32. Liu J, Xing $Y$, Hinds TR, Zheng J, Xu W. The third 20 amino acid repeat is the tightest binding site of APC for beta-catenin. J Mol Biol. 2006; 360:133-44.

33. Dupre-Crochet S, Figueroa A, Hogan C, Ferber EC, Bialucha CU, Adams J, et al. Casein kinase 1 is a novel negative regulator of $\mathrm{E}$-cadherin-based cell-cell contacts. Mol Cell Biol. 2007;27:3804-16.

34. Zeng X, Tamai K, Doble B, Li S, Huang H, Habas R, et al. A dual-kinase mechanism for Wnt co-receptor phosphorylation and activation. Nature. 2005:438:873-7.

35. Chitalia VC, Foy RL, Bachschmid MM, Zeng L, Panchenko MV, Zhou MI, et al. Jade-1 inhibits Wnt signalling by ubiquitylating beta-catenin and mediates Wnt pathway inhibition by pVHL. Nat Cell Biol. 2008;10:1208-16.

36. Borgal L, Rinschen MM, Dafinger C, Liebrecht VI, Abken H, Benzing T, et al. Jade-1S phosphorylation induced by CK1alpha contributes to cell cycle progression. Cell Cycle. 2016;15:1034-45.

37. Borgal L, Rinschen MM, Dafinger C, Hoff S, Reinert MJ, Lamkemeyer T, et al. Casein kinase 1 alpha phosphorylates the Wnt regulator Jade-1 and modulates its activity. J Biol Chem. 2014:289:26344-56.

38. Lebensohn AM, Dubey R, Neitzel LR, Tacchelly-Benites O, Yang E, Marceau $C D$, et al. Comparative genetic screens in human cells reveal new regulatory mechanisms in WNT signaling. elife. 2016;5:e21459.

39. Sanchez-Danes A, Hannezo E, Larsimont JC, Liagre M, Youssef KK, Simons $B D$, et al. Defining the clonal dynamics leading to mouse skin tumour initiation. Nature. 2016:536:298-303.

40. Snuderl M, Batista A, Kirkpatrick ND, Ruiz de Almodovar C, Riedemann L, Walsh EC, et al. Targeting placental growth factor/neuropilin 1 pathway inhibits growth and spread of medulloblastoma. Cell. 2013;152:1065-76.

41. Rubin LL, de Sauvage FJ. Targeting the hedgehog pathway in cancer. Nat Rev Drug Discov. 2006;5:1026-33.

42. Price MA, Kalderon D. Proteolysis of the hedgehog signaling effector Cubitus interruptus requires phosphorylation by glycogen synthase kinase 3 and casein kinase 1. Cell. 2002;108:823-35.

43. Lum L, Yao S, Mozer B, Rovescalli A, Von Kessler D, Nirenberg M, et al. Identification of hedgehog pathway components by RNAi in Drosophila cultured cells. Science. 2003:299:2039-45.

44. Jia J, Tong C, Wang B, Luo L, Jiang J. Hedgehog signalling activity of smoothened requires phosphorylation by protein kinase a and casein kinase I. Nature. 2004;432:1045-50. 
45. Zhang C, Williams EH, Guo Y, Lum L, Beachy PA. Extensive phosphorylation of smoothened in hedgehog pathway activation. Proc Natl Acad Sci U S A. 2004;101:17900-7.

46. Apionishev S, Katanayeva NM, Marks SA, Kalderon D, Tomlinson A. Drosophila smoothened phosphorylation sites essential for hedgehog signal transduction. Nat Cell Biol. 2005:7:86-92.

47. Evangelista M, Lim TY, Lee J, Parker L, Ashique A, Peterson AS, et al. Kinome siRNA screen identifies regulators of ciliogenesis and hedgehog signal transduction. Sci Signal. 2008;1:ra7.

48. Chen Y, Sasai N, Ma G, Yue T, Jia J, Briscoe J, et al. Sonic hedgehog dependent phosphorylation by CK1alpha and GRK2 is required for ciliary accumulation and activation of smoothened. PLoS Biol. 2011;9:e1001083.

49. Zhou BP, Hung MC. Wnt, hedgehog and snail: sister pathways that control by GSK-3beta and beta-Trcp in the regulation of metastasis. Cell Cycle. 2005; 4:772-6.

50. Kalderon D. Similarities between the hedgehog and Wnt signaling pathways. Trends Cell Biol. 2002;12:523-31.

51. Thorne CA, Hanson AJ, Schneider J, Tahinci E, Orton D, Cselenyi CS, et al. Small-molecule inhibition of Wnt signaling through activation of casein kinase 1alpha. Nat Chem Biol. 2010;6:829-36.

52. Li B, Fei DL, Flaveny CA, Dahmane N, Baubet V, Wang Z, et al. Pyrvinium attenuates hedgehog signaling downstream of smoothened. Cancer Res. 2014;74:4811-21.

53. Galluzzi L, Bravo-San Pedro JM, Levine B, Green DR, Kroemer G. Pharmacological modulation of autophagy: therapeutic potential and persisting obstacles. Nat Rev Drug Discov. 2017;16:487-511.

54. Levy JMM, Towers CG, Thorburn A. Targeting autophagy in cancer. Nat Rev Cancer. 2017;17:528-42.

55. Hara T, Mizushima N. Role of ULK-FIP200 complex in mammalian autophagy: FIP200, a counterpart of yeast Atg17? Autophagy. 2009;5: 85-7.

56. Mercer CA, Kaliappan A, Dennis PB. A novel, human Atg13 binding protein, Atg101, interacts with ULK1 and is essential for macroautophagy. Autophagy. 2009;5:649-62.

57. Hosokawa N, Sasaki T, lemura S, Natsume T, Hara T, Mizushima N. Atg101, a novel mammalian autophagy protein interacting with Atg13. Autophagy. 2009:5:973-9.

58. Petherick KJ, Conway OJ, Mpamhanga C, Osborne SA, Kamal A, Saxty B, et al. Pharmacological inhibition of ULK1 kinase blocks mammalian target of rapamycin (mTOR)-dependent autophagy. J Biol Chem. 2015;290:28726.

59. Russell RC, Tian Y, Yuan H, Park HW, Chang YY, Kim J, et al. ULK1 induces autophagy by phosphorylating Beclin-1 and activating VPS34 lipid kinase. Nat Cell Biol. 2013;15:741-50.

60. Di Bartolomeo S, Corazzari M, Nazio F, Oliverio S, Lisi G, Antonioli M, et al. The dynamic interaction of AMBRA1 with the dynein motor complex regulates mammalian autophagy. J Cell Biol. 2010;191:155-68.

61. Zhong Y, Wang QJ, Li X, Yan Y, Backer JM, Chait BT, et al. Distinct regulation of autophagic activity by Atg14L and Rubicon associated with Beclin 1phosphatidylinositol-3-kinase complex. Nat Cell Biol. 2009;11:468-76.

62. Matsunaga K, Saitoh T, Tabata K, Omori H, Satoh T, Kurotori N, et al. Two Beclin 1-binding proteins, Atg14L and Rubicon, reciprocally regulate autophagy at different stages. Nat Cell Biol. 2009;11:385-96.

63. Liang C, Feng P, Ku B, Dotan I, Canaani D, Oh BH, et al. Autophagic and tumour suppressor activity of a novel Beclin1-binding protein UVRAG. Nat Cell Biol. 2006:8:688-99.

64. Kim J, Kim YC, Fang C, Russell RC, Kim JH, Fan W, et al. Differential regulation of distinct Vps34 complexes by AMPK in nutrient stress and autophagy. Cell. 2013;152:290-303.

65. Suzuki K, Kirisako T, Kamada Y, Mizushima N, Noda T, Ohsumi Y. The preautophagosomal structure organized by concerted functions of APG genes is essential for autophagosome formation. EMBO J. 2001;20:5971-81.

66. Kabeya Y, Mizushima N, Ueno T, Yamamoto A, Kirisako T, Noda T, et al. LC3, a mammalian homologue of yeast Apg8p, is localized in autophagosome membranes after processing. EMBO J. 2000;19:5720-8.

67. Tanida I, Tanida-Miyake E, Ueno T, Kominami E. The human homolog of Saccharomyces cerevisiae Apg7p is a protein-activating enzyme for multiple substrates including human Apg12p, GATE-16, GABARAP, and MAP-LC3. J Biol Chem. 2001;276:1701-6.

68. Itakura E, Kishi-Itakura C, Mizushima N. The hairpin-type tail-anchored SNARE syntaxin 17 targets to autophagosomes for fusion with endosomes/ lysosomes. Cell. 2012;151:1256-69.
69. Zhao J, Brault JJ, Schild A, Cao P, Sandri M, Schiaffino S, et al. FoxO3 coordinately activates protein degradation by the autophagic/lysosomal and proteasomal pathways in atrophying muscle cells. Cell Metab. 2007;6:472-83.

70. Webb AE, Brunet A. FOXO transcription factors: key regulators of cellular quality control. Trends Biochem Sci. 2014;39:159-69.

71. Mammucari C, Milan G, Romanello V, Masiero E, Rudolf R, Del Piccolo P, et al. FoxO3 controls autophagy in skeletal muscle in vivo. Cell Metab. 2007;6: 458-71.

72. Cheong JK, Zhang F, Chua PJ, Bay BH, Thorburn A, Virshup DM. Casein kinase 1alpha-dependent feedback loop controls autophagy in RAS-driven cancers. J Clin Invest. 2015;125:1401-18.

73. Peterson TR, Laplante M, Thoreen CC, Sancak Y, Kang SA, Kuehl WM, et al. DEPTOR is an mTOR inhibitor frequently overexpressed in multiple myeloma cells and required for their survival. Cell. 2009;137:873-86.

74. Duan S, Skaar JR, Kuchay S, Toschi A, Kanarek N, Ben-Neriah Y, et al. mTOR generates an auto-amplification loop by triggering the betaTrCP-and CK1alpha-dependent degradation of DEPTOR. Mol Cell. 2011:44:317-24.

75. Zhao Y, Xiong X, Sun Y. DEPTOR, an mTOR inhibitor, is a physiological substrate of SCF(betaTrCP) E3 ubiquitin ligase and regulates survival and autophagy. Mol Cell. 2011;44:304-16.

76. Gao D, Inuzuka H, Tan MK, Fukushima H, Locasale JW, Liu P, et al. mTOR drives its own activation via SCF(betaTrCP)-dependent degradation of the mTOR inhibitor DEPTOR. Mol Cell. 2011;44:290-303.

77. Hale CM, Cheng Q, Ortuno D, Huang M, Nojima D, Kassner PD, et al. Identification of modulators of autophagic flux in an image-based high content siRNA screen. Autophagy. 2016;12:713-26.

78. Szyniarowski P, Corcelle-Termeau E, Farkas T, Hoyer-Hansen M, Nylandsted J, Kallunki T, et al. A comprehensive siRNA screen for kinases that suppress macroautophagy in optimal growth conditions. Autophagy. 2011;7:892-903.

79. Watanabe Y, Tsujimura A, Taguchi K, Tanaka M. HSF1 stress response pathway regulates autophagy receptor SQSTM1/p62-associated proteostasis. Autophagy. 2017;13:133-48.

80. Bowman BM, Sebolt KA, Hoff BA, Boes JL, Daniels DL, Heist KA, et al. Phosphorylation of FADD by the kinase CK1alpha promotes KRASG12Dinduced lung cancer. Sci Signal. 2015;8:ra9.

81. Cai J, Li R, Xu X, Zhang L, Lian R, Fang L, et al. CK1alpha suppresses lung tumour growth by stabilizing PTEN and inducing autophagy. Nat Cell Biol. 2018:20:465-78.

82. Sun SC. The non-canonical NF-kappaB pathway in immunity and inflammation. Nat Rev Immunol. 2017:17:545-58.

83. Wang $Y$, Sun $X$, Wu J, Xu BE, Gu C, Wang H, et al. Casein kinase 1alpha interacts with RIP1 and regulates NF-kappaB activation. Biochemistry. 2008; 47:441-8.

84. Beyaert R, Vanhaesebroeck B, Declercq W, Van Lint J, Vandenabele P, Agostinis $P$, et al. Casein kinase-1 phosphorylates the p75 tumor necrosis factor receptor and negatively regulates tumor necrosis factor signaling for apoptosis. J Biol Chem. 1995;270:23293-9.

85. Cho YS, Challa S, Moquin D, Genga R, Ray TD, Guildford M, et al. Phosphorylation-driven assembly of the RIP1-RIP3 complex regulates programmed necrosis and virus-induced inflammation. Cell. 2009;137: 1112-23.

86. Alappat EC, Feig C, Boyerinas B, Volkland J, Samuels M, Murmann AE, et al. Phosphorylation of FADD at serine 194 by CKlalpha regulates its nonapoptotic activities. Mol Cell. 2005;19:321-32.

87. Marikar FM, Jin G, Sheng W, Ma D, Hua Z. Metallothionein 2A an interactive protein linking phosphorylated FADD to NF-kappaB pathway leads to colorectal cancer formation. Chin Clin Oncol. 2016;5:76

88. Carvalho G, Le Guelte A, Demian C, Vazquez A, Gavard J, Bidere N. Interplay between BCL10, MALT1 and IkappaBalpha during T-cell-receptor-mediated NFkappaB activation. J Cell Sci. 2010;123:2375-80.

89. Martin M, Hua L, Wang B, Wei H, Prabhu L, Hartley AV, et al. Novel serine 176 phosphorylation of YBX1 activates NF-kappaB in Colon Cancer. J Biol Chem. 2017;292:3433-44

90. Otto T, Sicinski P. Cell cycle proteins as promising targets in cancer therapy. Nat Rev Cancer. 2017;17:93-115.

91. Gross SD, Simerly C, Schatten G, Anderson RA. A casein kinase I isoform is required for proper cell cycle progression in the fertilized mouse oocyte. $J$ Cell Sci. 1997:110(Pt 24):3083-90.

92. Honaker $\mathrm{Y}$, Piwnica-Worms $\mathrm{H}$. Casein kinase 1 functions as both penultimate and ultimate kinase in regulating Cdc25A destruction. Oncogene. 2010;29: 3324-34. 
93. Piao S, Lee SJ, Xu Y, Gwak J, Oh S, Park BJ, et al. CK1epsilon targets Cdc25A for ubiquitin-mediated proteolysis under normal conditions and in response to checkpoint activation. Cell Cycle. 2011;10:531-7.

94. Li L, Ren C, Yang G, Fattah EA, Goltsov AA, Kim SM, et al. GLIPR1 suppresses prostate cancer development through targeted oncoprotein destruction. Cancer Res. 2011;71:7694-704.

95. Huart AS, MacLaine NJ, Narayan V, Hupp TR. Exploiting the MDM2CK1alpha protein-protein interface to develop novel biologics that induce UBL-kinase-modification and inhibit cell growth. PLoS One. 2012 7:e43391.

96. Chen L, Li C, Pan Y, Chen J. Regulation of p53-MDMX interaction by casein kinase 1 alpha. Mol Cell Biol. 2005;25:6509-20.

97. MacLaine NJ, Oster B, Bundgaard B, Fraser JA, Buckner C, Lazo PA, et al. A central role for $C K 1$ in catalyzing phosphorylation of the p53 transactivation domain at serine 20 after HHV-6B viral infection. J Biol Chem. 2008;283: 28563-73.

98. Hirao A, Kong YY, Matsuoka S, Wakeham A, Ruland J, Yoshida H, et al. DNA damage-induced activation of p53 by the checkpoint kinase Chk2. Science. 2000;287:1824-7.

99. Shieh SY, Ahn J, Tamai K, Taya Y, Prives C. The human homologs of checkpoint kinases Chk1 and Cds1 (Chk2) phosphorylate p53 at multiple DNA damage-inducible sites. Genes Dev. 2000;14:289-300.

100. Li N, Lorenzi F, Kalakouti E, Normatova M, Babaei-Jadidi R, Tomlinson I, et al. FBXW7-mutated colorectal cancer cells exhibit aberrant expression of phosphorylated-p53 at Serine-15. Oncotarget. 2015;6:9240-56.

101. Dubois T, Rommel C, Howell S, Steinhussen U, Soneji Y, Morrice N, et al. 143-3 is phosphorylated by casein kinase I on residue 233. Phosphorylation at this site in vivo regulates Raf/14-3-3 interaction. J Biol Chem. 1997;272: 28882-8.

102. Qi ST, Wang ZB, Huang L, Liang LF, Xian YX, Ouyang YC, et al. Casein kinase 1 (alpha, delta and epsilon) localize at the spindle poles, but may not be essential for mammalian oocyte meiotic progression. Cell Cycle. 2015;14 1675-85.

103. Wang L, Lu A, Zhou HX, Sun R, Zhao J, Zhou CJ, et al. Casein kinase 1 alpha regulates chromosome congression and separation during mouse oocyte meiotic maturation and early embryo development. PLoS One. 2013;8: e63173

104. Schneider RK, Adema V, Heckl D, Jaras M, Mallo M, Lord AM, et al. Role of casein kinase $1 \mathrm{~A} 1$ in the biology and targeted therapy of del(5q) MDS. Cancer Cell. 2014;26:509-20.

105. Pribluda A, Elyada E, Wiener Z, Hamza H, Goldstein RE, Biton M, et al. A senescence-inflammatory switch from cancer-inhibitory to cancerpromoting mechanism. Cancer Cell. 2013;24:242-56.

106. Hu Y, Song W, Cirstea D, Lu D, Munshi NC, Anderson KC. CSNK1alpha1 mediates malignant plasma cell survival. Leukemia. 2015;29:474-82.

107. Nussbaum RL, Ellis CE. Alzheimer's disease and Parkinson's disease. N Engl J Med. 2003:348:1356-64.

108. Winblad B, Amouyel P, Andrieu S, Ballard C, Brayne C, Brodaty H, et al. Defeating Alzheimer's disease and other dementias: a priority for European science and society. Lancet Neurol. 2016;15:455-532.

109. Canter RG, Penney J, Tsai LH. The road to restoring neural circuits for the treatment of Alzheimer's disease. Nature. 2016;539:187-96.

110. Muller UC, Deller T, Korte M. Not just amyloid: physiological functions of the amyloid precursor protein family. Nat Rev Neurosci. 2017;18:281-98.

111. Yasojima K, Kuret J, DeMaggio AJ, McGeer E, McGeer PL. Casein kinase 1 delta mRNA is upregulated in Alzheimer disease brain. Brain Res. 2000;865: 116-20.

112. Flajolet M, He G, Heiman M, Lin A, Nairn AC, Greengard P. Regulation of Alzheimer's disease amyloid-beta formation by casein kinase I. Proc Natl Acad Sci U S A. 2007;104:4159-64

113. Walter J, Fluhrer R, Hartung B, Willem M, Kaether C, Capell A, et al. Phosphorylation regulates intracellular trafficking of beta-secretase. J Bio Chem. 2001;276:14634-41.

114. Buxbaum JD. A role for calsenilin and related proteins in multiple aspects of neuronal function. Biochem Biophys Res Commun. 2004;322:1140-4

115. Choi EK, Miller JS, Zaidi NF, Salih E, Buxbaum JD, Wasco W. Phosphorylation of calsenilin at Ser63 regulates its cleavage by caspase-3. Mol Cell Neurosci. 2003:23:495-506

116. Walter J, Capell A, Hung AY, Langen H, Schnolzer M, Thinakaran G, et al. Ectodomain phosphorylation of beta-amyloid precursor protein at two distinct cellular locations. J Biol Chem. 1997;272:1896-903.
117. Chauhan A, Chauhan VP, Murakami N, Brockerhoff H, Wisniewski HM. Amyloid beta-protein stimulates casein kinase I and casein kinase II activities. Brain Res. 1993;629:47-52.

118. Polanco JC, Li C, Bodea LG, Martinez-Marmol R, Meunier FA, Gotz J. Amyloid-beta and tau complexity - towards improved biomarkers and targeted therapies. Nat Rev Neurol. 2018;14:22-39.

119. de Calignon A, Fox LM, Pitstick R, Carlson GA, Bacskai BJ, Spires-Jones TL, et al. Caspase activation precedes and leads to tangles. Nature. 2010;464:1201-

120. Singh TJ, Grundke-lqbal I, lqbal K. Phosphorylation of tau protein by casein kinase-1 converts it to an abnormal Alzheimer-like state. J Neurochem. 1995; 64:1420-3.

121. Kuret J, Johnson GS, Cha D, Christenson ER, DeMaggio AJ, Hoekstra MF. Casein kinase 1 is tightly associated with paired-helical filaments isolated from Alzheimer's disease brain. J Neurochem. 1997:69:2506-15.

122. Wang C, Telpoukhovskaia MA, Bahr BA, Chen X, Gan L. Endo-lysosomal dysfunction: a converging mechanism in neurodegenerative diseases. Curr Opin Neurobiol. 2017:48:52-8.

123. Herrera A, Munoz P, Steinbusch HWM, Segura-Aguilar J. Are dopamine oxidation metabolites involved in the loss of dopaminergic neurons in the nigrostriatal system in Parkinson's disease? ACS Chem Neurosci. 2017:8:702-11.

124. Dehay B, Bourdenx M, Gorry P, Przedborski S, Vila M, Hunot S, et al. Targeting alpha-synuclein for treatment of Parkinson's disease: mechanistic and therapeutic considerations. Lancet Neurol. 2015;14:855-66.

125. Anderson JP, Walker DE, Goldstein JM, de Laat R, Banducci K, Caccavello RJ, et al. Phosphorylation of Ser-129 is the dominant pathological modification of alpha-synuclein in familial and sporadic Lewy body disease. J Biol Chem. 2006;281:29739-52.

126. Mbefo MK, Fares MB, Paleologou K, Oueslati A, Yin G, Tenreiro S, et al. Parkinson disease mutant E46K enhances alpha-synuclein phosphorylation in mammalian cell lines, in yeast, and in vivo. J Biol Chem. 2015;290:9412-27.

127. Okochi M, Walter J, Koyama A, Nakajo S, Baba M, Iwatsubo T, et al. Constitutive phosphorylation of the Parkinson's disease associated alphasynuclein. J Biol Chem. 2000;275:390-7.

128. Shanware NP, Williams LM, Bowler MJ, Tibbetts RS. Non-specific in vivo inhibition of CK1 by the pyridinyl imidazole p38 inhibitors SB 203580 and SB 202190. BMB Rep. 2009;42:142-7.

129. Liu FC, Graybiel AM. Spatiotemporal dynamics of CREB phosphorylation: transient versus sustained phosphorylation in the developing striatum. Neuron. 1996;17:1133-44.

130. Valente EM, Abou-Sleiman PM, Caputo V, Muqit MM, Harvey K, Gispert S, et al. Hereditary early-onset Parkinson's disease caused by mutations in PINK1. Science. 2004:304:1158-60.

131. Chia R, Haddock S, Beilina A, Rudenko IN, Mamais A, Kaganovich A, et al. Phosphorylation of LRRK2 by casein kinase 1alpha regulates trans-Golgi clustering via differential interaction with ARHGEF7. Nat Commun. 2014;5: 5827.

132. Yamamoto A, Friedlein A, Imai Y, Takahashi R, Kahle PJ, Haass C. Parkin phosphorylation and modulation of its E3 ubiquitin ligase activity. J Biol Chem. 2005;280:3390-9.

133. Cheung ZH, Fu AK, Ip NY. Synaptic roles of Cdk5: implications in higher cognitive functions and neurodegenerative diseases. Neuron. 2006;50:13-8.

134. Sharma P, Sharma M, Amin ND, Albers RW, Pant HC. Regulation of cyclindependent kinase 5 catalytic activity by phosphorylation. Proc Natl Acad Sci U S A. 1999:96:11156-60.

135. Liu F, Ma XH, Ule J, Bibb JA, Nishi A, DeMaggio AJ, et al. Regulation of cyclin-dependent kinase 5 and casein kinase 1 by metabotropic glutamate receptors. Proc Natl Acad Sci U S A. 2001;98:11062-8.

136. Simpson NH, Ceroni F, Reader RH, Covill LE, Knight JC, Consortium SLI, et al. Genome-wide analysis identifies a role for common copy number variants in specific language impairment. Eur J Hum Genet. 2015;23:1370-7.

137. Liu J, Carvalho LP, Bhattacharya S, Carbone CJ, Kumar KG, Leu NA, et al. Mammalian casein kinase 1alpha and its leishmanial ortholog regulate stability of IFNAR1 and type I interferon signaling. Mol Cell Biol. 2009:29: 6401-12.

138. Bhattacharya S, HuangFu WC, Liu J, Veeranki S, Baker DP, Koumenis C, et al. Inducible priming phosphorylation promotes ligand-independent degradation of the IFNAR1 chain of type I interferon receptor. J Biol Chem. 2010;285:2318-25. 
139. Zhang L, Li H, Chen Y, Gao X, Lu Z, Gao L, et al. The down-regulation of casein kinase 1 alpha as a host defense response against infectious bursal disease virus infection. Virology. 2017;512:211-21.

140. Xia C, Wolf JJ, Vijayan M, Studstill CJ, Ma W, Hahm B. Casein kinase 1alpha mediates degradation of receptors for type I and type II interferons caused by hemagglutinin of influenza a virus. J Virol. 2018;92:e00006-18.

141. Chong R, Squires R, Swiss R, Agaisse H. RNAi screen reveals host cell kinases specifically involved in listeria monocytogenes spread from cell to cell. PLoS One. 2011;6:e23399.

142. Wang Z, Wang S, Wang W, Gu Y, Liu H, Wei F, et al. Targeted disruption of CK1alpha in toxoplasma gondii increases acute virulence in mice. Eur J Protistol. 2016;56:90-101.

143. Eichwald C, Jacob G, Muszynski B, Allende JE, Burrone OR. Uncoupling substrate and activation functions of rotavirus NSP5: phosphorylation of Ser-67 by casein kinase 1 is essential for hyperphosphorylation. Proc Natl Acad Sci U S A. 2004;101: 16304-9.

144. Campagna M, Budini M, Arnoldi F, Desselberger U, Allende JE, Burrone OR. Impaired hyperphosphorylation of rotavirus NSP5 in cells depleted of casein kinase 1alpha is associated with the formation of viroplasms with altered morphology and a moderate decrease in virus replication. J Gen Virol. 2007; 88:2800-10

145. Quintavalle M, Sambucini S, Di Pietro C, De Francesco R, Neddermann P. The alpha isoform of protein kinase CKI is responsible for hepatitis $C$ virus NS5A hyperphosphorylation. J Virol. 2006;80:11305-12.

146. Sudha G, Yamunadevi S, Tyagi N, Das S, Srinivasan N. Structural and molecular basis of interaction of HCV non-structural protein 5A with human casein kinase 1alpha and PKR. BMC Struct Biol. 2012;12:28.

147. Bhattacharya D, Ansari $I H$, Striker R. The flaviviral methyltransferase is a substrate of casein kinase 1. Virus Res. 2009;141:101-4.

148. Lin TC, Su CY, Wu PY, Lai TC, Pan WA, Jan YH, et al. The nucleolar protein NIFK promotes cancer progression via CK1alpha/beta-catenin in metastasis and Ki-67-dependent cell proliferation. Elife. 2016;5:e11288.

149. Richter J, Kretz AL, Lemke J, Fauler M, Werner JU, Paschke S, et al. CK1alpha overexpression correlates with poor survival in colorectal cancer. BMC Cancer. 2018;18:140.

150. Sarasqueta AF, Forte G, Corver WE, de Miranda NF, Ruano D, van Eijk R, et al. Integral analysis of p53 and its value as prognostic factor in sporadic colon cancer. BMC Cancer. 2013:13:277.

151. Katlinskaya W, Katlinski KV, Lasri A, Li N, Beiting DP, Durham AC, et al. Type I interferons control proliferation and function of the intestinal epithelium. Mol Cell Biol. 2016;36:1124-35

152. Zhang P, Bill K, Liu J, Young E, Peng T, Bolshakov S, et al. MiR-155 is a liposarcoma oncogene that targets casein kinase-1alpha and enhances beta-catenin signaling. Cancer Res. 2012;72:1751-62.

153. Prasad R, Katiyar SK. Ultraviolet radiation-induced inflammation activates beta-catenin signaling in mouse skin and skin tumors. Int J Oncol. 2014;44 1199-206.

154. Boultwood J, Pellagatti A, Cattan H, Lawrie CH, Giagounidis A, Malcovati L, et al. Gene expression profiling of CD34+ cells in patients with the $5 q$ syndrome. Br J Haematol. 2007;139:578-89.

155. Bello E, Pellagatti A, Shaw J, Mecucci C, Kusec R, Killick S, et al. CSNK1A1 mutations and gene expression analysis in myelodysplastic syndromes with del(5q). Br J Haematol. 2015;171:210-4.

156. Smith AE, Kulasekararaj AG, Jiang J, Mian S, Mohamedali A, Gaken J, et al. CSNK1A1 mutations and isolated del(5q) abnormality in myelodysplastic syndrome: a retrospective mutational analysis. Lancet Haematol. 2015;2:e212-21.

157. Kataoka K, Nagata Y, Kitanaka A, Shiraishi Y, Shimamura T, Yasunaga J, et al. Integrated molecular analysis of adult T cell leukemia/lymphoma. Nat Genet. 2015;47:1304-15.

158. Sato Y, Yoshizato T, Shiraishi Y, Maekawa S, Okuno Y, Kamura T, et al. Integrated molecular analysis of clear-cell renal cell carcinoma. Nat Genet. 2013:45:860-7.

159. Okerberg ES, Hainley A, Brown H, Aban A, Alemayehu S, Shih A, et al. Identification of a tumor specific, active-site mutation in casein kinase 1alpha by chemical proteomics. PLoS One. 2016;11:e0152934.

160. Dulak AM, Stojanov P, Peng S, Lawrence MS, Fox C, Stewart C, et al. Exome and whole-genome sequencing of esophageal adenocarcinoma identifies recurrent driver events and mutational complexity. Nat Genet. 2013;45:478-86.

161. Manni S, Carrino M, Piazza F. Role of protein kinases CK1alpha and CK2 in multiple myeloma: regulation of pivotal survival and stress-managing pathways. J Hematol Oncol. 2017;10:157.
162. List A, Kurtin S, Roe DJ, Buresh A, Mahadevan D, Fuchs D, et al. Efficacy of lenalidomide in myelodysplastic syndromes. N Engl J Med. 2005;352:549-57.

163. List A, Dewald G, Bennett J, Giagounidis A, Raza A, Feldman E, et al. Lenalidomide in the myelodysplastic syndrome with chromosome $5 q$ deletion. N Engl J Med. 2006;355:1456-65.

164. Fenaux P, Giagounidis A, Selleslag D, Beyne-Rauzy O, Mufti G, Mittelman M, et al. A randomized phase 3 study of lenalidomide versus placebo in RBC transfusion-dependent patients with low-/Intermediate-1-risk myelodysplastic syndromes with del5q. Blood. 2011;118:3765-76.

165. Nguyen TV, Li J, Lu CJ, Mamrosh JL, Lu G, Cathers BE, et al. p97NCP promotes degradation of CRBN substrate glutamine synthetase and neosubstrates. Proc Natl Acad Sci U S A. 2017;114:3565-71.

166. Li X, Liu J, Gao T. Beta-TrCP-mediated ubiquitination and degradation of PHLPP1 are negatively regulated by Akt. Mol Cell Biol. 2009;29:6192-205.

167. Mai H, Xu X, Mei G, Hong T, Huang J, Wang T, et al. The interplay between HPIP and casein kinase 1alpha promotes renal cell carcinoma growth and metastasis via activation of mTOR pathway. Oncogene. 2016:5:e260.

168. Sun D, Zhou M, Kowolik CM, Trisal V, Huang Q, Kernstine KH, et al. Differential expression patterns of capping protein, protein phosphatase 1 , and casein kinase 1 may serve as diagnostic markers for malignant melanoma. Melanoma Res. 2011;21:335-43.

169. Sinnberg T, Menzel M, Kaesler S, Biedermann T, Sauer B, Nahnsen S, et al. Suppression of casein kinase 1alpha in melanoma cells induces a switch in beta-catenin signaling to promote metastasis. Cancer Res. 2010;70:6999-7009.

170. Sinnberg T, Wang J, Sauer B, Schittek B. Casein kinase 1alpha has a nonredundant and dominant role within the CK1 family in melanoma progression. BMC Cancer. 2016;16:594.

171. Manni S, Carrino M, Manzoni M, Gianesin K, Nunes SC, Costacurta M, et al. Inactivation of CK1alpha in multiple myeloma empowers drug cytotoxicity by affecting AKT and beta-catenin survival signaling pathways. Oncotarget. 2017:8:14604-19.

172. Yang $Y$, Shaffer AL 3rd, Emre NC, Ceribelli M, Zhang M, Wright G, et al. Exploiting synthetic lethality for the therapy of $A B C$ diffuse large $B$ cell lymphoma. Cancer Cell. 2012;21:723-37.

173. Zhou A, Lin K, Zhang S, Chen Y, Zhang N, Xue J, et al. Nuclear GSK3beta promotes tumorigenesis by phosphorylating KDM1A and inducing its deubiquitylation by USP22. Nat Cell Biol. 2016;18:954-66.

174. Magliozzi R, Low TY, Weijts BG, Cheng T, Spanjaard E, Mohammed S, et al. Control of epithelial cell migration and invasion by the IKKbeta- and CK1alpha-mediated degradation of RAPGEF2. Dev Cell. 2013;27:574-85.

175. Zhao Y, Qin S, Atangan LI, Molina Y, Okawa Y, Arpawong HT, et al. Casein kinase 1alpha interacts with retinoid $X$ receptor and interferes with agonistinduced apoptosis. J Biol Chem. 2004;279:30844-9.

176. Desagher S, Osen-Sand A, Montessuit S, Magnenat E, Vilbois F, Hochmann A, et al. Phosphorylation of bid by casein kinases I and II regulates its cleavage by caspase 8. Mol Cell. 2001;8:601-11.

177. Grills C, Jithesh PV, Blayney J, Zhang SD, Fennell DA. Gene expression metaanalysis identifies VDAC1 as a predictor of poor outcome in early stage non-small cell lung cancer. PLoS One. 2011;6:e14635.

178. Srivastava M, Khurana P, Sugadev R. Lung cancer signature biomarkers: tissue specific semantic similarity based clustering of digital differential display (DDD) data. BMC Res Notes. 2012;5:617.

179. Lantermann AB, Chen D, McCutcheon K, Hoffman G, Frias E, Ruddy D, et al. Inhibition of casein kinase 1 alpha prevents acquired drug resistance to Erlotinib in EGFR-mutant non-small cell lung Cancer. Cancer Res. 2015;75: 4937-48.

180. Loh YN, Hedditch EL, Baker LA, Jary E, Ward RL, Ford CE. The Wnt signalling pathway is upregulated in an in vitro model of acquired tamoxifen resistant breast cancer. BMC Cancer. 2013;13:174

181. Kuo IY, Wu CC, Chang JM, Huang YL, Lin CH, Yan JJ, et al. Low SOX17 expression is a prognostic factor and drives transcriptional dysregulation and esophageal cancer progression. Int J Cancer. 2014;135:563-73.

182. Litlekalsoy J, Rostad K, Kalland KH, Hostmark JG, Laerum OD. Expression of circadian clock genes and proteins in urothelial cancer is related to cancerassociated genes. BMC Cancer. 2016;16:549.

183. Kattapuram T, Yang S, Maki JL, Stone JR. Protein kinase CK1alpha regulates mRNA binding by heterogeneous nuclear ribonucleoprotein $C$ in response to physiologic levels of hydrogen peroxide. J Biol Chem. 2005;280:15340-7.

184. Mohan N, Sudheesh AP, Francis N, Anderson R, Laishram RS. Phosphorylation regulates the star-PAP-PIPKlalpha interaction and directs specificity toward mRNA targets. Nucleic Acids Res. 2015;43:7005-20. 
185. Golden RJ, Chen B, Li T, Braun J, Manjunath H, Chen X, et al. An Argonaute phosphorylation cycle promotes microRNA-mediated silencing. Nature. 2017;542:197-202.

186. Carreras Puigvert J, von Stechow L, Siddappa R, Pines A, Bahjat M, Haazen LC, et al. Systems biology approach identifies the kinase Csnk1a1 as a regulator of the DNA damage response in embryonic stem cells. Sci Signal. 2013;6:ra5

187. Van Camp JK, Beckers S, Zegers D, Van Hul W. Wnt signaling and the control of human stem cell fate. Stem Cell Rev. 2014;10:207-29.

188. Harwood AJ. Signal transduction in development: holding the key. Dev Cell. 2002:2:384-5.

189. Dimova N, Wysoczynski M, Rokosh G. Stromal cell derived factor-1alpha promotes C-kit+ cardiac stem/progenitor cell quiescence through casein kinase 1alpha and GSK3beta. Stem Cells. 2014;32:487-99.

190. Ursu A, Illich DJ, Takemoto Y, Porfetye AT, Zhang M, Brockmeyer A, et al. Epiblastin a induces reprogramming of epiblast stem cells into embryonic stem cells by inhibition of casein kinase 1. Cell Chem Biol. 2016;23:494-507.

191. Illich DJ, Zhang M, Ursu A, Osorno R, Kim KP, Yoon J, et al. Distinct signaling requirements for the establishment of ESC pluripotency in late-stage EpiSCs. Cell Rep. 2016;15:787-800.

192. Bao X, Siprashvili Z, Zarnegar BJ, Shenoy RM, Rios EJ, Nady N, et al. CSNK1a1 regulates PRMT1 to maintain the progenitor state in self-renewing somatic tissue. Dev Cell. 2017:43:227-39. e5

193. Gui J, Zhao B, Lyu K, Tong W, Fuchs SY. Downregulation of the IFNAR1 chain of type 1 interferon receptor contributes to the maintenance of the haematopoietic stem cells. Cancer Biol Ther. 2017;18:534-43.

194. Waugh MG, Challiss RA, Berstein G, Nahorski SR, Tobin AB. Agonist-induced desensitization and phosphorylation of m1-muscarinic receptors. Biochem J. 1999;338(Pt 1):175-83.

195. Tobin AB, Keys B, Nahorski SR. Identification of a novel receptor kinase that phosphorylates a phospholipase C-linked muscarinic receptor. J Biol Chem. 1996:271:3907-16.

196. Tobin AB, Totty NF, Sterlin AE, Nahorski SR. Stimulus-dependent phosphorylation of G-protein-coupled receptors by casein kinase 1alpha. J Biol Chem. 1997;272:20844-9.

197. Hauser AS, Attwood MM, Rask-Andersen M, Schioth HB, Gloriam DE. Trends in GPCR drug discovery: new agents, targets and indications. Nat Rev Drug Discov. 2017;16:829-42.

198. Turner KM, Burgoyne RD, Morgan A. Protein phosphorylation and the regulation of synaptic membrane traffic. Trends Neurosci. 1999;22:459-64.

199. Hirota T, Lee JW, Lewis WG, Zhang EE, Breton G, Liu X, et al. Highthroughput chemical screen identifies a novel potent modulator of cellular circadian rhythms and reveals CKlalpha as a clock regulatory kinase. PLoS Biol. 2010;8:e1000559.

200. Ugrankar R, Berglund E, Akdemir F, Tran C, Kim MS, Noh J, et al. Drosophila glucome screening identifies Ck1alpha as a regulator of mammalian glucose metabolism. Nat Commun. 2015;6:7102.

201. Zelenak C, Eberhard M, Jilani K, Qadri SM, Macek B, Lang F. Protein kinase CK1alpha regulates erythrocyte survival. Cell Physiol Biochem. 2012;29:171-80

202. Nguyen HQ, Nye J, Buster DW, Klebba JE, Rogers GC, Bosco G. Drosophila casein kinase I alpha regulates homolog pairing and genome organization by modulating condensin II subunit cap-H2 levels. PLoS Genet. 2015;11: e1005014.

203. Yan Q, Chen J, Li W, Bao C, Fu Q. Targeting miR-155 to treat experimental scleroderma. Sci Rep. 2016;6:20314.

204. Li X, He L, Yue Q, Lu J, Kang N, Xu X, et al. MiR-9-5p promotes MSC migration by activating beta-catenin signaling pathway. Am J Physiol Cell Physiol. 2017;313:C80-93.

205. Kuga T, Kume H, Adachi J, Kawasaki N, Shimizu M, Hoshino I, et al. Casein kinase 1 is recruited to nuclear speckles by FAM83H and SON. Sci Rep. 2016; 6:34472.

206. Cruciat CM, Dolde C, de Groot RE, Ohkawara B, Reinhard C, Korswagen HC, et al. RNA helicase DDX3 is a regulatory subunit of casein kinase 1 in Wntbeta-catenin signaling. Science. 2013;339:1436-41.

207. Lindner S, Kronke J. The molecular mechanism of thalidomide analogs in hematologic malignancies. J Mol Med (Berl). 2016;94:1327-34

208. Chijiwa T, Hagiwara M, Hidaka H. A newly synthesized selective casein kinase I inhibitor, N-(2-aminoethyl)-5-chloroisoquinoline-8-sulfonamide, and affinity purification of casein kinase I from bovine testis. J Biol Chem. 1989; 264:4924-7.
209. Nyati S, Ranga R, Ross BD, Rehemtulla A, Bhojani MS. Molecular imaging of glycogen synthase kinase-3beta and casein kinase-1alpha kinases. Anal Biochem. 2010;405:246-54.

210. Burzio V, Antonelli M, Allende CC, Allende JE. Biochemical and cellular characteristics of the four splice variants of protein kinase CK1alpha from zebrafish (Danio rerio). J Cell Biochem. 2002;86:805-14.

211. Behrend L, Milne DM, Stoter M, Deppert W, Campbell LE, Meek DW, et al. IC261, a specific inhibitor of the protein kinases casein kinase 1-delta and -epsilon, triggers the mitotic checkpoint and induces p53dependent postmitotic effects. Oncogene. 2000;19:5303-13.

212. Kurihara T, Sakurai E, Toyomoto M, Kii I, Kawamoto D, Asada T, et al. Alleviation of behavioral hypersensitivity in mouse models of inflammatory pain with two structurally different casein kinase 1 (CK1) inhibitors. Mol Pain. 2014;10:17.

213. Muraki M, Ohkawara B, Hosoya T, Onogi H, Koizumi J, Koizumi T, et al, Manipulation of alternative splicing by a newly developed inhibitor of Clks. J Biol Chem. 2004;279:24246-54.

214. Isojima Y, Nakajima M, Ukai H, Fujishima H, Yamada RG, Masumoto KH, et al. CKlepsilon/delta-dependent phosphorylation is a temperatureinsensitive, period-determining process in the mammalian circadian clock. Proc Natl Acad Sci U S A. 2009;106:15744-9.

215. Anastassiadis T, Deacon SW, Devarajan K, Ma H, Peterson JR. Comprehensive assay of kinase catalytic activity reveals features of kinase inhibitor selectivity. Nat Biotechnol. 2011;29:1039-45.

216. Rena G, Bain J, Elliott M, Cohen P. D4476, a cell-permeant inhibitor of CK1, suppresses the site-specific phosphorylation and nuclear exclusion of FOXO1a. EMBO Rep. 2004;5:60-5.

217. Sarafidis PA, Georgianos PI, Lasaridis AN. Diuretics in clinical practice. Part I: mechanisms of action, pharmacological effects and clinical indications of diuretic compounds. Expert Opin Drug Saf. 2010;9:243-57.

218. Ishii I, Harada Y, Kasahara T. Reprofiling a classical anthelmintic, pyrvinium pamoate, as an anti-cancer drug targeting mitochondrial respiration. Front Oncol. 2012;2:137

219. Li B, Flaveny CA, Giambelli C, Fei DL, Han L, Hang Bl, et al. Repurposing the FDA-approved pinworm drug pyrvinium as a novel chemotherapeutic agent for intestinal polyposis. PLoS One. 2014;9:e101969.

220. Saraswati S, Alfaro MP, Thorne CA, Atkinson J, Lee E, Young PP. Pyrvinium, a potent small molecule Wnt inhibitor, promotes wound repair and post-Ml cardiac remodeling. PLoS One. 2010;5:e15521.

221. Venerando A, Girardi C, Ruzzene M, Pinna LA. Pyrvinium pamoate does not activate protein kinase CK1, but promotes Akt/PKB down-regulation and GSK3 activation. Biochem J. 2013;452:131-7.

222. Barham W, Frump AL, Sherrill TP, Garcia CB, Saito-Diaz K, Van Saun MN, et al. Targeting the Wnt pathway in synovial sarcoma models. Cancer Discov. 2013:3:1286-301.

223. Li B, Orton D, Neitzel LR, Astudillo L, Shen C, Long J, et al. Differential abundance of CK1alpha provides selectivity for pharmacological CK1alpha activators to target WNT-dependent tumors. Sci Signal. 2017;10:eaak9916.

224. Li B, Lee E, Robbins DJ. Casein kinaselalpha activators, a precision weapon for CRC. Oncotarget. 2017;8:96462-3.

225. laconelli J, Huang JH, Berkovitch SS, Chattopadhyay S, Mazitschek R, Schreiber SL, et al. HDAC6 inhibitors modulate Lys49 acetylation and membrane localization of beta-catenin in human iPSC-derived neuronal cells. ACS Chem Biol. 2015;10:883-90.

226. Brockman JL, Anderson RA. Casein kinase I is regulated by phosphatidylinositol 4,5-bisphosphate in native membranes. J Biol Chem. 1991;266:2508-12.

227. Bazenet CE, Brockman JL, Lewis D, Chan C, Anderson RA. Erythroid membranebound protein kinase binds to a membrane component and is regulated by phosphatidylinositol 4,5-bisphosphate. J Biol Chem. 1990;265:7369-76.

228. Knippschild U, Gocht A, Wolff S, Huber N, Lohler J, Stoter M. The casein kinase 1 family: participation in multiple cellular processes in eukaryotes. Cell Signal. 2005;17:675-89.

229. Budini M, Jacob G, Jedlicki A, Perez C, Allende CC, Allende JE. Autophosphorylation of carboxy-terminal residues inhibits the activity of protein kinase CK1alpha. J Cell Biochem. 2009;106:399-408.

230. Chang $\mathrm{CH}$, Kuo CJ, Ito T, Su YY, Jiang ST, Chiu MH, et al. CK1alpha ablation in keratinocytes induces p53-dependent, sunburn-protective skin hyperpigmentation. Proc Natl Acad Sci U S A. 2017;114:E8035-E44.

231. Green CL, Bennett GS. Identification of four alternatively spliced isoforms of chicken casein kinase I alpha that are all expressed in diverse cell types. Gene. 1998;216:189-95. 
232. Yong TJ, Gan YY, Toh BH, Sentry JW. Human CKlalpha(L) and CKlalpha(S) are encoded by both 2.4- and 4. 2-kb transcripts, the longer containing multiple RNA-destablising elements. Biochim Biophys Acta. 2000;1492:425-33.

233. Zhang J, Gross SD, Schroeder MD, Anderson RA. Casein kinase I alpha and alpha L: alternative splicing-generated kinases exhibit different catalytic properties. Biochemistry. 1996;35:16319-27.

234. Panchenko MP, Siddiquee Z, Dombkowski DM, Alekseyev YO, Lenburg ME, Walker JD, et al. Protein kinase CK1alphaLS promotes vascular cell proliferation and intimal hyperplasia. Am J Pathol. 2010;177:1562-72.

235. Wang $H$, Albadawi $H$, Siddiquee $Z$, Stone JM, Panchenko MP, Watkins MT, et al. Altered vascular activation due to deficiency of the NADPH oxidase component p22phox. Cardiovasc Pathol. 2014;23:35-42.

236. Nousiainen M, Sillje HH, Sauer G, Nigg EA, Korner R. Phosphoproteome analysis of the human mitotic spindle. Proc Natl Acad Sci U S A. 2006;103: 5391-6.

237. Ohyashiki JH, Ohyashiki K, Sandberg AA, Minowada J, Kinniburgh AJ. Human-fms gene is retained in acute lymphoblastic leukemia cells with del(5)(q32). Cancer Genet Cytogenet. 1987;25:341-50.

238. Consortium GT. The genotype-tissue expression (GTEx) project. Nat Genet. 2013;45:580-5.

239. Consortium GT, Laboratory DA, Coordinating Center -Analysis Working G, Statistical Methods groups-Analysis Working G, Enhancing Gg, Fund NIHC, et al. Genetic effects on gene expression across human tissues. Nature. 2017:550:204-13.

240. Uhlen M, Fagerberg L, Hallstrom BM, Lindskog C, Oksvold P, Mardinoglu A et al. Proteomics. Tissue-based map of the human proteome. Science. 2015; 347:1260419.

241. Cancer Genome Atlas Research N, Weinstein JN, Collisson EA, Mills GB, Shaw KR, Ozenberger BA, et al. The Cancer genome atlas Pan-Cancer analysis project. Nat Genet. 2013;45:1113-20.

242. Rhodes DR, Yu J, Shanker K, Deshpande N, Varambally R, Ghosh D, et al. ONCOMINE: a cancer microarray database and integrated data-mining platform. Neoplasia. 2004;6:1-6.

243. Segara D, Biankin AV, Kench JG, Langusch CC, Dawson AC, Skalicky DA, et al. Expression of $\mathrm{HOXB2}$, a retinoic acid signaling target in pancreatic cancer and pancreatic intraepithelial neoplasia. Clin Cancer Res. 2005;11:3587-96.

244. Pei H, Li L, Fridley BL, Jenkins GD, Kalari KR, Lingle W, et al. FKBP51 affects cancer cell response to chemotherapy by negatively regulating Akt. Cancer Cell. 2009;16:259-66.

245. Sun L, Hui AM, Su Q, Vortmeyer A, Kotliarov Y, Pastorino S, et al. Neuronal and glioma-derived stem cell factor induces angiogenesis within the brain. Cancer Cell. 2006;9:287-300.

246. Piccaluga PP, Agostinelli C, Califano A, Rossi M, Basso K, Zupo S, et al. Gene expression analysis of peripheral T cell lymphoma, unspecified, reveals distinct profiles and new potential therapeutic targets. J Clin Invest. 2007; 117:823-34.

247. Hu N, Clifford RJ, Yang HH, Wang C, Goldstein AM, Ding T, et al. Genome wide analysis of DNA copy number neutral loss of heterozygosity (CNNLOH) and its relation to gene expression in esophageal squamous cell carcinoma. BMC Genomics. 2010;11:576.

248. Kim SM, Park YY, Park ES, Cho JY, Izzo JG, Zhang D, et al. Prognostic biomarkers for esophageal adenocarcinoma identified by analysis of tumor transcriptome. PLoS One. 2010;5:e15074.

249. Lee JS, Leem SH, Lee SY, Kim SC, Park ES, Kim SB, et al. Expression signature of E2F1 and its associated genes predict superficial to invasive progression of bladder tumors. J Clin Oncol. 2010;28:2660-7.

250. Ginos MA, Page GP, Michalowicz BS, Patel KJ, Volker SE, Pambuccian SE, et al. Identification of a gene expression signature associated with recurrent disease in squamous cell carcinoma of the head and neck. Cancer Res. 2004;64:55-63

251. Thul PJ, Akesson L, Wiking M, Mahdessian D, Geladaki A, Ait Blal H, et al. A subcellular map of the human proteome. Science. 2017;356:eaal3321.

252. Kahn M. Can we safely target the WNT pathway? Nat Rev Drug Discov. 2014;13:513-32

253. Young RM, Staudt LM. Targeting pathological B cell receptor signalling in lymphoid malignancies. Nat Rev Drug Discov. 2013;12:229-43.

254. Li MO, Rudensky AY. T cell receptor signalling in the control of regulatory $T$ cell differentiation and function. Nat Rev Immunol. 2016;16:220-33.

255. Moynagh PN. The roles of Pellino E3 ubiquitin ligases in immunity. Nat Rev Immunol. 2014;14:122-31.
256. Chen J, Chen ZJ. Regulation of NF-kappaB by ubiquitination. Curr Opin Immunol. 2013;25:4-12.

257. Akira S, Takeda K. Toll-like receptor signalling. Nat Rev Immunol. 2004;4:499-511.

258. Schapira AH, Olanow CW, Greenamyre JT, Bezard E. Slowing of neurodegeneration in Parkinson's disease and Huntington's disease: future therapeutic perspectives. Lancet. 2014;384:545-55.

259. Vaughan RA, Foster JD. Mechanisms of dopamine transporter regulation in normal and disease states. Trends Pharmacol Sci. 2013;34:489-96.

260. Bidere N. Role of CK1alpha in adaptive immunity and lymphomagenesis. Med Sci (Paris). 2009;25:454-6.

261. Wang B, Wei H, Prabhu L, Zhao W, Martin M, Hartley AV, et al. Role of novel serine 316 phosphorylation of the p65 subunit of NF-kappaB in differential gene regulation. J Biol Chem. 2015;290:20336-47.

\section{Ready to submit your research? Choose BMC and benefit from:}

- fast, convenient online submission

- thorough peer review by experienced researchers in your field

- rapid publication on acceptance

- support for research data, including large and complex data types

- gold Open Access which fosters wider collaboration and increased citations

- maximum visibility for your research: over $100 \mathrm{M}$ website views per year

At BMC, research is always in progress.

Learn more biomedcentral.com/submissions 